This is the peer reviewed version of the following article: ChemCatChem 2020, 12, 5236-5249, which has been published in final form at https://doi.org/10.1002/cctc.202000787. This article may be used for non-commercial purposes in accordance with Wiley Terms and Conditions for Use of Self-Archived Versions.

\title{
Insights into the production of upgraded biofuels using Mg-loaded mesoporous ZSM-5 zeolites
}

Olga Sanahuja-Parejo, ${ }^{[\mathrm{a}]}$ Alberto Veses, ${ }^{[\mathrm{a}]}$ José Manuel López ${ }^{[\mathrm{a}]}$, María Soledad Callén, ${ }^{[\mathrm{a}]}$ Benjamín Solsona, ${ }^{[\mathrm{b}]}$ Nia Richards, ${ }^{[\mathrm{c}]}$ Stuart H. Taylor, ${ }^{[\mathrm{c}]}$ Tomás García, ${ }^{*}$, [a]

[a] O. Sanahuja-Parejo, Dr. A.Veses, Dr, J.M. López, Dr. M.S Callén, Dr. T. García Environmental Research Group Instituto de Carboquímica (ICB-CSIC); twitter: @ICB_CSIC,

C/ Miguel Luesma Castán, 50018 Zaragoza

E-mail: tomas@icb.csic.es; twitter:@icbTomas

[b] Dr. B. Solsona

Department of Chemical Engineering Universitat de Valencia

C/ Dr. Moliner 50, 46100 Burjassot, Valencia, Spain.

[c] Dr. Nia Richards, Prof. S.H. Taylor

Cardiff Catalysis Institute, School of Chemistry; twitter: @CCI_Cardiff

Cardiff University, Main Building, Park Place, Cardiff, CF10 3AT, UK

Supporting information for this article is given via a link at the end of the document.

Abstract: Bio-oil catalytic upgrading has been performed using mesoporous Mg-loaded ZSM-5. The presence of $\mathrm{Mg}$ modifies both textural and acidic properties, which do not only depend on the $\mathrm{Mg}$ content (1 and 5 wt.\%) but also on the $\mathrm{Si} / \mathrm{Al}$ ratio of the parent zeolite (25 and 40). Mg impregnation over mesoporous acidic zeolites has been shown to be essential for further deoxygenation of the raw bio-oil. Thus, remarkable deoxygenation rates have been achieved, exceeding $68 \%$ for a $5 \mathrm{wt} . \% \mathrm{Mg}$-loaded ZSM$5(\mathrm{Si} / \mathrm{Al}=25)$. For this catalyst, decarboxylation reactions at $\mathrm{MgO}$ active sites seem to be predominant, promoting the upgrading of phenols towards the formation of phenolic compounds with lower oxygen content. As in the case of acidic mesoporous ZSM-5, the formation of aromatics for Mg-loaded mesoporous ZSM-5 samples could be mainly related to the promotion of decarbonylation reactions of phenolic compounds over Brønsted acidic sites at the external surface. Interestingly, the presence of strong Lewis acidic sites created by the interaction between $\left(\mathrm{Mg}^{2+} \mathrm{OH}^{-}\right)^{+}$species and extra framework alumina jointly with the remaining Brønsted acidic sites at the external surface could enhance the 
This is the peer reviewed version of the following article: ChemCatChem 2020, 12, 5236-5249, which has been published in final form at https://doi.org/10.1002/cctc.202000787. This article may be used for non-commercial purposes in accordance with Wiley Terms and Conditions for Use of Self-Archived Versions.

formation of aromatics through cascade reactions involving ketonization and further aldol condensation and dehydration reactions.

\section{Introduction}

The current high demand for energy has led to an increase in fuel production, and consequently, a progressive decrease in fossil resources. Therefore, in the last decades, several alternatives are being investigated to generate liquid fuels from renewable sources that can be considered environmentallyfriendly (i.e. reducing greenhouse gases and environmental impact). Complying with these requirements, lignocellulosic biomass emerges as one of the most attractive sources of renewable energy ${ }^{[1]}$.

Pyrolysis of lignocellulosic biomass arises as an attractive solution ${ }^{[2]}$, since it is the only thermochemical process that can produce liquid biofuels (bio-oil), in a single step and in a relatively simple way at moderate temperature and atmospheric pressure ${ }^{[1 \mathrm{~b}, 2 \mathrm{a}]}$. Bio-oils consist of a complex mixture, mainly oxygenated compounds, such as phenolic compounds, carboxylic acids, aldehydes, ketones and furan derivatives, conferring the mixture several characteristic properties that prevents compatibility with current petroleum-based infrastructures. The high oxygen content of bio-oil (30-40\% $)^{[3]}$, increases its polarity, lowers its calorific value and makes it corrosive and immiscible with hydrocarbons ${ }^{[1 b, 4]}$. Thus, it is necessary to perform an upgrading process of the bio-oil in order to incorporate it into current infrastructures.

Currently, there are different bio-oil upgrading techniques focused on elimination of oxygen in the organic fraction, which can be divided into two different groups: in situ and ex situ. Interestingly, the development of a technology combining both, by means of catalytic pyrolysis and either secondary hydro deoxygenation of the bio-oil using some nickel or cobalt metal-based materials ${ }^{[5]}$, or catalytic cracking of the generated vapors using zeolite-based catalysts ${ }^{[6]}$, seem to be the most promising routes. In both processes, the use of heterogeneous catalysts appears as a fundamental requirement to promote specific reactions, converting the oxygen-containing compounds present in bio-oil into more valuable compounds, such as light aromatics. Whilst low-cost minerals seem to be one of the best choices for in situ catalytic pyrolysis processes ${ }^{[7]}$, due to their inherent characteristics (biomass ashes are deposited on the catalyst surface after char combustion for catalyst heating and regeneration). Cracking catalysts based on zeolites can be precisely designed for ex situ processes dealing with the generated vapors, since the contact between biomass feedstock and catalyst is avoided. Specifically, it has been demonstrated that acidic HZSM-5 zeolites are the most promising catalysts for ex situ cracking catalytic processes, due to their ideal pore size, shape selectivity and controllable acidity, that enhances aromatization reactions, acting as an optimal starting point in the further design of catalysts. Against this background, the presence of 
This is the peer reviewed version of the following article: ChemCatChem 2020, 12, 5236-5249, which has been published in final form at https://doi.org/10.1002/cctc.202000787. This article may be used for non-commercial purposes in accordance with Wiley Terms and Conditions for Use of Self-Archived Versions.

molecular diffusion limitations to the HZSM-5 active sites is well-known ${ }^{[8]}$. Consequently, the aromatic yield obtained after bio-oil upgrading has been greatly improved after generating catalyst mesoporosity [1a, 4, 9]. Two main factors of tailor-made mesoporous acidic HZSM-5 zeolites play a fundamental role in the catalytic cracking of bio-oil, these are the number of strong Brønsted acidic sites, and the development of mesoporosity. Indeed, we have observed that the accessibility to the acid sites on the external surface of the catalyst is the factor that controls the yield to aromatics ${ }^{[1 \mathrm{a}, 10]}$, contributing to the cracking and oligomerization of the generated olefins ${ }^{[9 a, 10 b, 11]}$. Although bio-oil upgrading takes place through a complex deoxygenation process, promoted by various mechanisms, such as dehydration $\left(\mathrm{H}_{2} \mathrm{O}\right)$, decarboxylation $\left(\mathrm{CO}_{2}\right)$ and decarbonylation $(\mathrm{CO})$ reactions ${ }^{[2 a, 9 b, 10 b]}$, the latter mechanism has been demonstrated to be prevalent for tailor-made mesoporous acidic HZSM-5 zeolites.

It is generally proposed that a potential route for the development of an improved catalyst for the production of upgraded bio-fuels could rely on the incorporation of metallic species into mesoporous zeolites, leading to bifunctional catalysts. The incorporation of new metal active sites, together with the presence of the pristine Brønsted acidic sites, could favor the presence of cascade-type reactions, leading to a bio-oil with improved properties ${ }^{[11]},{ }^{[12]}$. The routes to incorporate metallic species are diverse, including wet impregnation ${ }^{[11]}$, incipient wetness impregnation ${ }^{[13]}$ and ion exchange ${ }^{[14]}$. Metal species can be supported as nanoparticles on the external surface of the catalyst or be integrated into the zeolites as extraframework cations at the exchange positions. In previous studies, it has been observed that the incorporation of different metallic species (Ni, Ga, Zn, Co, Fe, Zn and Mg) ${ }^{[11-12,14-15]}$, significantly influences the deoxygenation reaction mechanism during the upgrading of bio-oil. It should be noted that $\mathrm{Zn}$ - and Ga-loaded zeolites are reported to promote aromatization pathways, maximizing the BTX (Benzene, Toluene and Xylene) production, via decarbonylation at metal active sites and further oligomerization of bio-oil vapors ${ }^{[16]}$. In the case of $\mathrm{Ni}$, Co or Fe-loaded zeolites, its capacity to produce in-situ $\mathrm{H}_{2}$ at metal sites can favor dehydrogenation-dehydration reactions to produce a moredeoxygenated and valuable aromatic-rich bio-oil ${ }^{[14,15 \mathrm{c}]}$. Conversely, we have reported that whilst the new active sites created after wet impregnation of 1 wt.\% Mg-loading on mesoporous ZSM-5 (Si/Al:40), increase the bio-oil deoxygenation rate throughout decarboxylation and decarbonylation reactions, a biooil with a lower aromatic content was obtained ${ }^{[6,11]}$. This has been related to the lower amount of Brønsted acidic sites remaining in the zeolite after Mg impregnation. In particular, it has been observed that whilst the new active sites created after Mg-loading in the zeolites could promote ketonization of acids and aldehydes significantly increasing the deoxygenation rate, further aldol condensation reactions towards aromatics production at the Brønsted acidic sites are restricted ${ }^{[1]}$. Hence, the nature and position of the metal active sites in the zeolite can be considered as key factors that influence the catalytic activity and 
This is the peer reviewed version of the following article: ChemCatChem 2020, 12, 5236-5249, which has been published in final form at https://doi.org/10.1002/cctc.202000787. This article may be used for non-commercial purposes in accordance with Wiley Terms and Conditions for Use of Self-Archived Versions.

the selectivity of the products. Accordingly, finding an optimum distribution between new Lewis metal acidic sites and pristine Brønsted acidic sites in Mg-loaded HZSM-5 zeolites, arises as a challenge in biooil upgrading. Ideally a catalyst should promote high deoxygenation rates, and also increase the yield to light aromatics. However, to the best of our knowledge, no attempt has been made to optimize Mg-loaded mesoporous ZSM-5 zeolites towards the production of highly-deoxygenated and rich-aromatic biofuels, despite the exceptional deoxygenation rate previously reported with a $1 \mathrm{wt} \% \mathrm{Mg}$-loaded mesoporous ZSM-5 (Si/Al:40) zeolite.

In this study, the production of upgraded bio-fuel through the catalytic cracking of pyrolytic bio-oil vapors over Mg-loaded ZSM-5 mesoporous zeolites has been studied in a fixed-bed reactor. Mesoporous acidic ZSM-5 samples have been obtained from two different parent ZSM-5 commercial zeolites (Si/A1 of 25 and 40 at.). 1 and 5 wt.\% Mg-loaded zeolites have been prepared using an incipient wetness impregnation method. Detailed characterization of the zeolites, including $\mathrm{N}_{2}$ adsorption, X-ray Diffraction (XRD), Transmission Electron Microscopy (TEM), X-ray Photoelectron Spectroscopy (XPS), AmmoniumTemperature Programmed Desorption (NH3-TPD), Pyridine- Diffuse Reflectance Infrared Fourier Transform Spectroscopy (Py-DRIFTS) and Solid-state Magic Angle Spinning Nuclear Magnetic Resonance (MAS NMR) have been performed, in order to elucidate the role of the textural and acidic zeolite parameters on the production of the upgraded biofuel. Accordingly, different properties of the biooil have been determined, such as $\mathrm{pH}$, total acid number (TAN), water content, elemental analysis, higher heating value (HHV) and chemical composition by Gas Chromatography / Mass Spectrometry (GC / MS). Additionally, non-condensable gases have been identified by GC using a Thermal Conductivity Detector (TCD).

\section{Results and Discussion}

\section{Catalyst characterization}

The phase purity and crystallinity of the zeolite samples were verified by XRD (see Figure 1). For a better comparison of the catalysts, microporous HZSM-5 zeolites $(\mathrm{Si} / \mathrm{Al}=25$ and 40$)$ and mesoporous counterparts were also included. For all zeolites, the patterns displayed sharp reflections, with characteristic peaks at $2 \Theta=6-9^{\circ}$ and $22.5-25^{\circ}$, corresponding to the MFI structure. The absence of any $\mathrm{Mg}$-containing crystalline phases is not surprising, as loadings higher than $10 \%$ of $\mathrm{MgO}$ are reported to be needed ${ }^{[17]}$. Nevertheless, it cannot be totally ruled out that this fact is indicative of either the amorphous character of the metal species, and/or the presence of well-dispersed small nanoparticles on the external zeolite surface. As reported for cation-loaded mesoporous zeolites ${ }^{[18]}$, mesoporosity can favor the 
This is the peer reviewed version of the following article: ChemCatChem 2020, 12, 5236-5249, which has been published in final form at https://doi.org/10.1002/cctc.202000787. This article may be used for non-commercial purposes in accordance with Wiley Terms and Conditions for Use of Self-Archived Versions.

dispersion of metal oxide nanoparticles over the zeolitic support, owing to its additional surface area. Additionally, it is worth commenting that $\mathrm{Mg}$ species could be incorporated as extraframework metal cations at specific exchange sites ${ }^{[11,19]}$. In line with this, it is accepted that the low-angle XRD intensities in the pattern of the zeolite are sensitive to the presence of any species inside the internal channels, as it can be clearly appreciated in the case of the MgHZ25-1 pattern (Figure 1), where lower intensity peaks are observed.

Porous properties of the hierarchically structured catalysts are also summarized in Table 1. After the impregnation process, textural properties of the zeolites, such as the BET surface area and pore volume, are modified, as can be observed in Table 1. BET surface area decreased upon metal incorporation, possibly due to both the partial blockage of zeolite pores by well-dispersed metal species at the external surface and the incorporation of $\mathrm{Mg}$ cations at the internal extraframework exchange positions ${ }^{[20]}$. On the other hand, $\mathrm{V}_{\text {MESO }}$ exhibits very interesting behavior, since mesopore volume is preserved in the case of the 1 wt.\% Mg-loaded HZ25 zeolite. Prevalent incorporation of Mg at the specific exchange sites of its internal zeolitic structure could explain this feature. This is in agreement with its noticeable framework distortion, observed by XRD and further confirmed by ${ }^{27}$ Al MAS NMR (Figure 4). Conversely, a marked decrease in the mesopore volume of the other Mg-loaded mesoporous zeolites was observed, especially at high Mg loadings, suggesting that Mg species could be mainly deposited on the external surface during the impregnation step. Finally, as shown later by NMR, it cannot be ruled out that dealumination and desilication processes also have an effect on the zeolite porous properties after $\mathrm{Mg}$ impregnation.
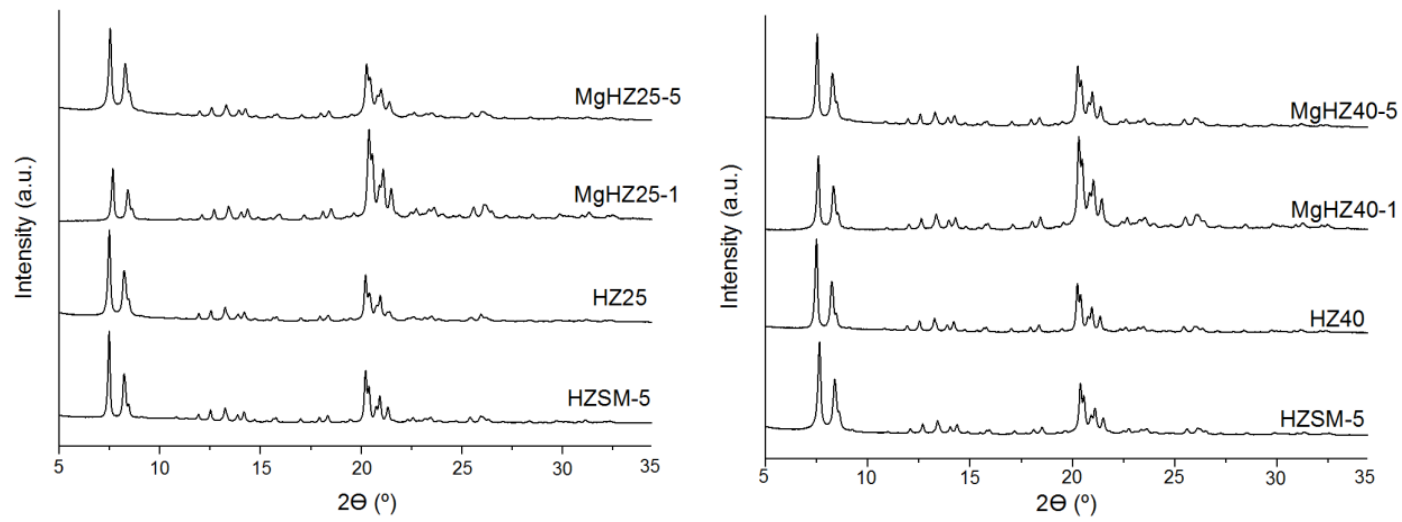

Figure 1. XRD patterns of the commercial, mesoporous and Mg-loaded ZSM-5 zeolites. 
This is the peer reviewed version of the following article: ChemCatChem 2020, 12, 5236-5249, which has been published in final form at https://doi.org/10.1002/cctc.202000787. This article may be used for non-commercial purposes in accordance with Wiley Terms and Conditions for Use of Self-Archived Versions.
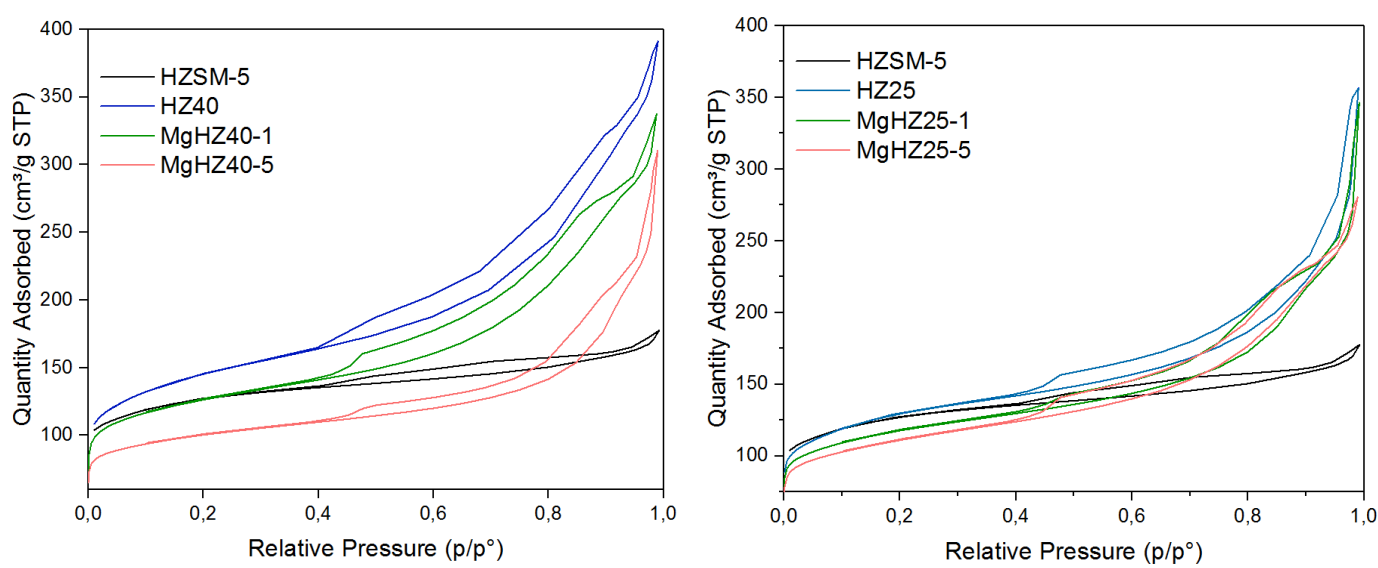

Figure 2. Nitrogen isotherms of the Mg-loaded hierarchical zeolites.

Nitrogen adsorption isotherms are shown in Figure 2. It can be observed that the conventional HZSM-5 zeolites exhibited a typical type $\mathrm{I}$ isotherm with a limited uptake of $\mathrm{N}_{2}$ at higher relative pressures. Different shapes of hysteresis loops (sharp step-down of the desorption branch) have been reported and associated with different pore structures ${ }^{[21]}$. Thus, a H4-loop can be also observed, confirming that conventional HZSM-5 zeolites also have inter-particle porosity ${ }^{[22]}$. On the contrary, mesoporous acidic zeolites and Mg-loaded zeolites exhibit a type IV isotherm, characteristic of mesoporous solids. The increased $\mathrm{N}_{2}$ uptake at high relative pressures $\left(\mathrm{p} / \mathrm{p}_{0}>0.5\right)$ clearly indicates mesoporous properties. All mesoporous zeolites exhibit a H5-hysteresis loop that can be associated with structures containing both open and partially blocked mesopores. Significant differences can be found in the $\mathrm{N}_{2}$ adsorption isotherms, depending on both the $\mathrm{Mg}$ loading and the $\mathrm{Si} / \mathrm{Al}$ ratio. The differences could be related to a distinct balance between the number of $\mathrm{Mg}$ species at the external zeolite surface and the amount of $\mathrm{Mg}$ metal cations at the internal specific exchange positions, as already commented ${ }^{[18,23]}$. First, it is worth mentioning that, at relative pressure ( $\left.\mathrm{p} / \mathrm{p}_{0}\right)$ higher than 0.4 , the $\mathrm{N}_{2}$ adsorption uptake in $\mathrm{MgHZ25-1}$ is comparable to that observed for MgHZ25-5, except at relative pressures close to 1, again indicating that $\mathrm{Mg}$ species could be mainly incorporated as Mg cations at the internal specific exchange sites in the case of 1 wt.\% Mg-loaded zeolites with $\mathrm{Si} / \mathrm{Al}=25$, whilst $\mathrm{Mg}$ species are also deposited on the external surface area at high $\mathrm{Mg}$ loading. A different trend has been observed for $\mathrm{Si} / \mathrm{Al}=40$ zeolites, where a marked lower $\mathrm{N}_{2}$ uptake at low and high relative pressures were evident for Mg-loaded zeolites, compared to HZ40, suggesting that $\mathrm{Mg}$ species, either $\mathrm{Mg}$ at a specific exchange position, or $\mathrm{MgO}$ nanoparticles, could be preferentially incorporated onto the external surface area (external surface and mesopores), partly blocking the entrance to the internal microporosity. 
This is the peer reviewed version of the following article: ChemCatChem 2020, 12, 5236-5249, which has been published in final form at https://doi.org/10.1002/cctc.202000787. This article may be used for non-commercial purposes in accordance with Wiley Terms and Conditions for Use of Self-Archived Versions.

Table 1. EDX, XPS and Porous and Acidic Characteristics of Acidic and Cation-Loaded Hierarchical Zeolites.

\begin{tabular}{lllllll}
\hline Zeolite & $\begin{array}{c}\text { SBET } \\
\mathbf{m}^{\mathbf{2} / \mathbf{g}}\end{array}$ & $\begin{array}{c}\text { VMESO } \\
\mathbf{c m}^{\mathbf{3}} / \mathbf{g}\end{array}$ & $\begin{array}{l}\text { EDX }^{[\mathbf{a}]} \\
\text { Mg, wt.\% }\end{array}$ & $\begin{array}{l}\mathbf{E D X}^{[\mathbf{a}]} \\
\text { Si/Al at. }\end{array}$ & $\begin{array}{l}\mathbf{X P S}^{[\mathbf{b}]} \\
\text { Mg, wt.\% }\end{array}$ & $\begin{array}{l}\mathbf{X P S}^{[\mathbf{b}]} \\
\text { Si/Al at. }\end{array}$ \\
\hline HZ25 & 460.5 & 0.38 & --- & n.d & --- & 13 \\
MgHZ25-1 & 431.5 & 0.41 & 1.5 & 16 & 1.1 & 9 \\
MgHZ25-5 & 407.9 & 0.32 & 4.6 & 14 & 3.6 & 5 \\
HZ40 & 528.0 & 0.54 & --- & n.d & --- & 19 \\
MgHZ40-1 & 462.9 & 0.40 & 1.3 & 23 & 1.1 & 11 \\
MgHZ40-5 & 372.2 & 0.37 & 5.0 & 19 & 5.7 & 5 \\
\hline
\end{tabular}

n.d. : not determined. [a] bulk composition. [b] surface composition

Solid State NMR was performed on all catalysts to determine the species of $\mathrm{Si}, \mathrm{Al}$ and $\mathrm{H}$ present. The ${ }^{29} \mathrm{Si}$ spectra in Figure 3 shows HZ25 to have both $\mathrm{Q}^{3}$ and $\mathrm{Q}^{4}$ species ${ }^{[24]}$. $\mathrm{Q}^{3}$ at $-104 \mathrm{ppm}$ refers to Si atoms that are bound to $3 \mathrm{Si}$ and $1 \mathrm{Al}$ atom via oxygen atoms, whilst $\mathrm{Q}^{4}$ at $-111 \mathrm{ppm}$ refers to $\mathrm{Si}$ atoms that are bound to $4 \mathrm{Si}$ atoms via oxygen atoms. As the loading of $\mathrm{Mg}$ increases to $1 \mathrm{wt} . \%$ the number of $\mathrm{Q}^{3}$ species decreases, whilst the number of Q4 species increases, indicating that a dealumination process with further $\mathrm{SiO}_{2}$ reconstruction could be taking place. On the other hand, the intensity of $\mathrm{Q}^{3}$ and $\mathrm{Q}^{4}$ species is decreased at $5 \mathrm{wt} . \% \mathrm{Mg}$ loading, pointing out possible desilication and dealumination processes at high Mg loadings. A slightly different ${ }^{29} \mathrm{Si}$ spectrum is obtained for the HZ40 catalyst, since $\mathrm{Q}^{3}$ species were not substantially modified after $\mathrm{Mg}$ impregnation, denoting that mostly non-framework $\mathrm{Al}$ species and $\mathrm{Q}^{4} \mathrm{Si}$ atoms could be involved in the dealumination and dealumination/desilication processes accounted for 1 and $5 \mathrm{wt} . \% \mathrm{Mg}$-loaded HZ40 samples, respectively.

The ${ }^{27} \mathrm{Al}$ spectra in Figure 4 shows HZ25 to have only 4-coordinated Al species present, but when $\mathrm{Mg}$ is added there is a mix of both 4 - and 6-coordinated species. The change in the Al species denoted by ${ }^{27} \mathrm{Al}$ MAS NMR after addition of Mg indicates that the structure of the zeolite has changed and the lattice has been disrupted ${ }^{[24 a, 25]}$. 4-coordinated $\mathrm{Al}$ is found within the zeolite framework (Framework Al, FAL), whereas the 6-coordinated species belong to extra framework Al species (Extra Framework Al, EFAL) ${ }^{[26]}$.Therefore, the ${ }^{27} \mathrm{AlNMR}$ spectra of HZ25 would suggest, that whilst there are no EFAL species in the parent zeolite, these species are formed by means of a dealumination process after $\mathrm{Mg}$ impregnation [17, 27], and they are more apparent for MgHZ25-1. This agrees with XRD data, where a framework distortion is observed for this sample, and also with $\mathrm{N}_{2}$ adsorption results, since mesoporosity is preserved or even slightly increased in comparison to the parent mesoporous acidic zeolite (from 0.38 to $0.41 \mathrm{~cm}^{3} / \mathrm{g}$ ). 
This is the peer reviewed version of the following article: Chem CatChem 2020, 12, 5236-5249, which has been published in final form at https://doi.org/10.1002/cctc.202000787. This article may be used for non-commercial purposes in accordance with Wiley Terms and Conditions for Use of Self-Archived Versions.

It should be pointed out, that since EFAL can account for both Bronsted and Lewis acidity ${ }^{[26]}$, the acidity of this sample will be significantly modified. In the case of the HZ40 series, both 6-coordinated EFAL and 4-coordinated FAL species are present in the unmodified zeolite, being their intensity reduced as $\mathrm{Mg}$ loading was increased. This fact could be again linked to a dealumination process after $\mathrm{Mg}$ impregnation, with Al removal being more effective at high Mg loadings, as almost all EFAL species disappeared. Finally, the resonance at $-40 \mathrm{ppm}$ on the HZ25 spectra is a spinning side band and it is not representative of different Al species.
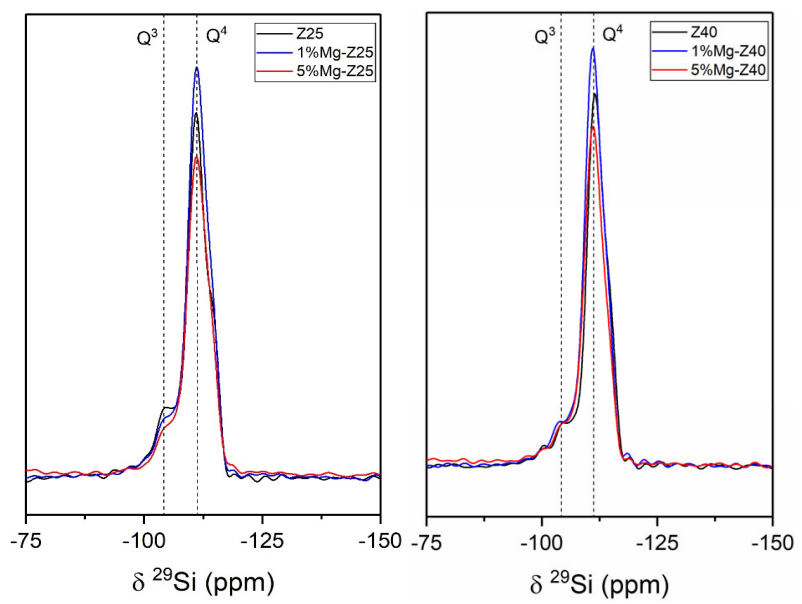

Figure 3. ${ }^{29} \mathrm{Si}$ MAS NMR spectra of the studied samples, the left spectra belong to a HZ25 series, while the right belongs to a HZ40 series. The resonances are assigned to the various Si coordination environments. Legend: Black - support, blue - $1 \% \mathrm{Mg}$, red - $5 \% \mathrm{Mg}$.

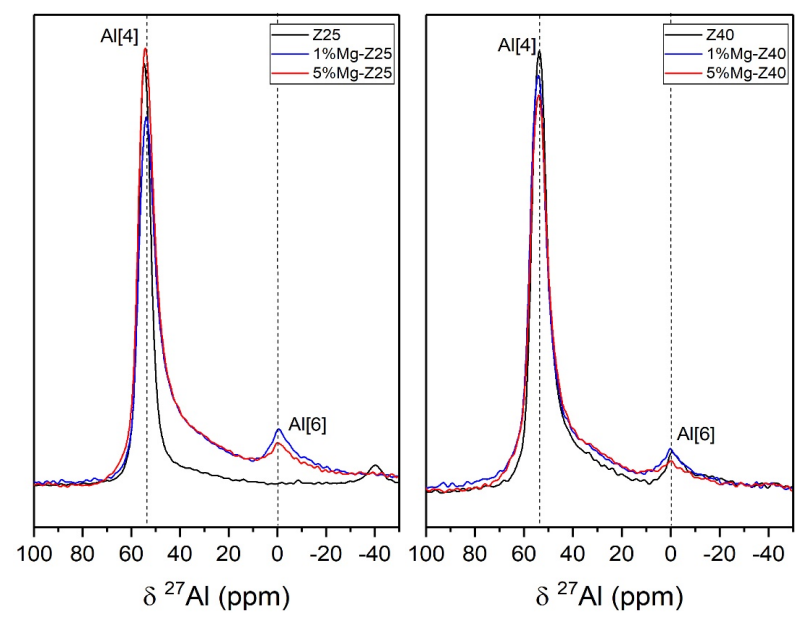

Figure 4. ${ }^{27} \mathrm{Al}$ MAS NMR spectra of the studied samples, the left spectra belong to a Z25 series, while the right belongs to a Z40 series. The resonances are assigned to the various Al coordination environments. Legend: Black - support, blue - $1 \% \mathrm{Mg}$, red - $5 \% \mathrm{Mg}$. 
This is the peer reviewed version of the following article: ChemCatChem 2020, 12, 5236-5249, which has been published in final form at https://doi.org/10.1002/cctc.202000787. This article may be used for non-commercial purposes in accordance with Wiley Terms and Conditions for Use of Self-Archived Versions.

Figure 5 shows that the proton spectra of the HZ25 consists of resonances due to acidic OH groups and OH from non-framework Al. Similarly, the undoped HZ40 sample shows the same features ${ }^{[28]}$. However, when $\mathrm{Mg}$ is impregnated a new resonance at $c a .6 .5 \mathrm{ppm}$, linked to the presence of protons in either $\mathrm{OH}$ or $\mathrm{H}_{2} \mathrm{O}$ in a hydrogen bonded environment is observed for all $\mathrm{Mg}$-loaded samples, regardless of both the $\mathrm{Si} / \mathrm{Al}$ ratio and the $\mathrm{Mg}$ content. According to literature data ${ }^{[26,29]}$, this resonance could arise from the formation of new Lewis acidic sites, $\left(\mathrm{Mg}^{2+} \mathrm{OH}^{-}\right)^{+}$species, as $\mathrm{Mg}$ replaces the hydroxyl group in the ZSM5 structure. For HZ25 series, this feature is more prominent in the case of the MgHZ25-1 sample, indicating that there are more Lewis acidic sites than in the MgHZ25-5 catalyst, even though the Mg loading is increased in the latter. Therefore, $\mathrm{Mg}$ incipient wetness impregnation does not only lead to incorporation to specific exchanged positions but also, in line with ${ }^{27} \mathrm{Al}$ MAS NMR data, could create new EFAL species, eventually leading to the increase in the number and strength of Lewis acidic sites, as shown later by Py-DRIFTS. These seem to be caused by a strong interaction between $\left(\mathrm{Mg}^{2+} \mathrm{OH}^{-}\right)^{+}$and EFAL species ${ }^{[26]}$. As mentioned above, $\left(\mathrm{Mg}^{2+} \mathrm{OH}^{-}\right)^{+}$species are significantly decreased for MgHZ25-5, since these species could condense to form $\mathrm{MgO}$ at high $\mathrm{Mg}$ loadings ${ }^{[26]}$. Therefore, although the number of $\mathrm{Mg}$ species available at specific exchange sites in the internal zeolitic structure are decreased for MgHZ25-5, MgO species could be formed within the internal mesoporosity. This is in agreement with XPS data, where an internal zeolite structure enriched in $\mathrm{Mg}^{2+}$ species was detected (see Table 1). A different evolution in the distribution of the acidic sites was seen for the HZ40 series. Accordingly, Figure 5 displays that $\left(\mathrm{Mg}^{2+} \mathrm{OH}^{-}\right)^{+}$species were significantly increased with the $\mathrm{Mg}$ content, showing a proton spectra comparable to the MgHZ25-1 sample. However, as observed in Figure 4, EFAL species present in the parent HZ40, were greatly decreased after Mg impregnation, being marginal in the case of MgHZ40-5. Therefore, the strong interaction between $\left(\mathrm{Mg}^{2+} \mathrm{OH}^{-}\right)^{+}$and EFAL species leading to strong 
This is the peer reviewed version of the following article: Chem CatChem 2020, 12, 5236-5249, which has been published in final form at https://doi.org/10.1002/cctc.202000787. This article may be used for non-commercial purposes in accordance with Wiley Terms and Conditions for Use of Self-Archived Versions.

Lewis active sites would be prevented. Summarizing, different distributions in the number and strength of acidic sites are obtained for each sample, depending on both the $\mathrm{Si} / \mathrm{Al}$ ratio and the $\mathrm{Mg}$ loading.
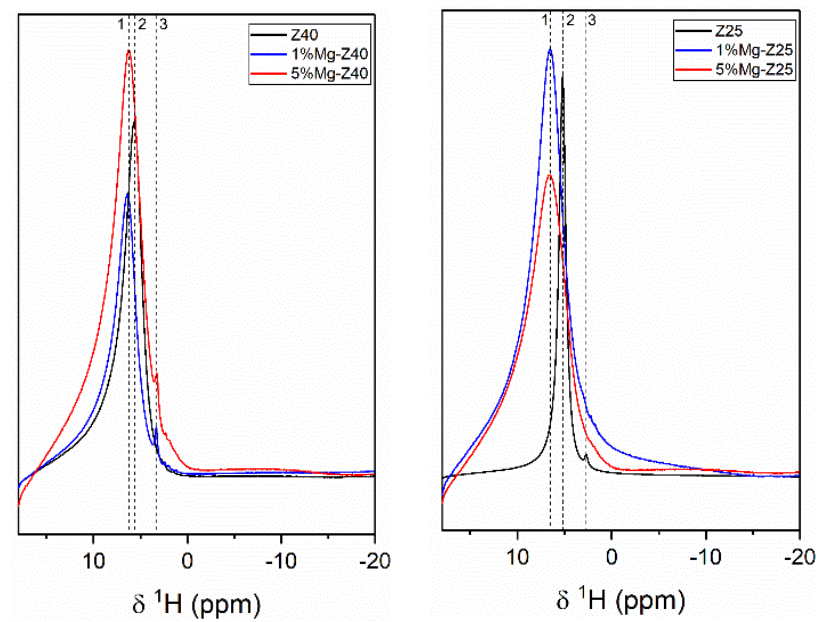

Figure 5. ${ }^{1} \mathrm{H}$ MAS NMR spectra of the studied samples, the left spectra belong to Z25 series, while the right belong to a Z40 series. The resonances are assigned to the various proton environments. Legend: Black - support, blue - $1 \% \mathrm{Mg}$, red - $5 \% \mathrm{Mg}$. The broadness of the spectra denotes that there is a lot of mobile water on the surface that has been adsorbed during the $\mathrm{Mg}$ addition.

Transmission electron microscopy (TEM) was also performed. Typical TEM images of the different samples are shown in Figure 6. The morphologies of these samples are quasi-similar and consist of agglomerations and connected nanoparticles with sizes ranging from 10 to $20 \mathrm{~nm}$. The nanoparticles are neatly organized into a mesoporous structure. Also, it is of interest to emphasize that some areas of the material consist of domains with bigger grains, with dimensions about $200 \mathrm{~nm}$, especially in the case of the MgHZ40-5 sample.

High Resolution (HR)TEM analyses were performed to study and to identify the crystalline phases present in the MgHZ25-1 sample (Figure S1). As seen from direct measurement of spacing in between the crystal fringes visualized in the HRTEM image, and from its FFT pattern, the interplanar distance is about $1 \mathrm{~nm}$. The observed distance between fringes in the HRTEM image could be attributed to the (101) plane of the ZSM-5 matrix. The most noticeable finding from HRTEM analyses is that no characteristic peaks of lattice impurities are observed. Interestingly, the result shows no evidence for the presence of metallic $\mathrm{Mg}$ and/or $\mathrm{MgO}$ compounds on the matrix. The absence of any crystalline phases is indicative of either the amorphous character of the $\mathrm{MgO}$ species, and/or the presence of $\mathrm{Mg}$ cations at the specific exchange positions. These results agree with the XRD data, where no reflections of crystalline $\mathrm{Mg}$ species were detected. 
This is the peer reviewed version of the following article: ChemCatChem 2020, 12, 5236-5249, which has been published in final form at https://doi.org/10.1002/cctc.202000787. This article may be used for non-commercial purposes in accordance with Wiley Terms and Conditions for Use of Self-Archived Versions.

All Mg-containing catalysts synthesized were also analyzed by EDX-TEM microscopy. The quantitative composition of the samples was determined by measuring extensive areas of the samples and the composition was found to be rather uniform (Table 1). Bulk Mg compositions close to those theoretically expected were detected for all the samples.

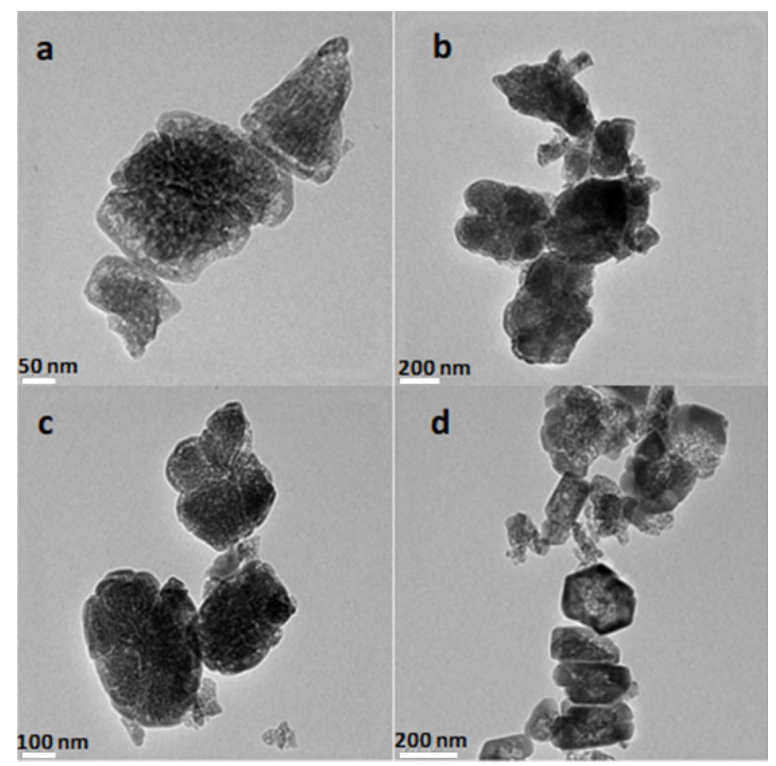

Figure 6. TEM micrographs of (a) MgHZ25-1, (a) MgHZ25-5, (c) MgHZ40-1 and (d) MgHZ40-5 catalysts.

XPS analysis was performed and results are presented in Table 1 and also in the Supporting Information (Figure S2). The O 1s spectra of all studied samples had a single peak at binding energy of $c a .532 .9 \mathrm{eV}$ that can be attributed to the Si-O-Si bond. This fact was also confirmed in the Si $2 p$ spectra, where all the samples showed one single peak at BE $c a .103 .3 \mathrm{eV}$. The Al 2p spectra showed a single peak at $c a$. 74.4 $\mathrm{eV}$ for all samples, corresponding to the aluminosilicate, except for the samples with $1 \mathrm{wt} . \%$ loading of $\mathrm{Mg}$. Finally, the $\mathrm{Mg} 2 \mathrm{p}$ spectra are also shown in Figure S2. Although the Mg $2 p$ signal is weak, especially for the 1 wt.\% loaded samples, the peak was positioned at $c a .50 .8 \mathrm{eV}$ for all catalysts, which is a characteristic value for $\mathrm{MgO}$ species ${ }^{[30]}$.

Surface and bulk elemental compositions are compared in Table 1. XPS and EDX analyses of HZ25 and HZ40 samples loaded with 1 wt.\% Mg confirm that a significant amount of $\mathrm{Mg}$ was incorporated at the specific internal exchange sites after impregnation (Table 1), since bulk Mg composition determined by EDX (1.5 and 1.3 wt.\%) was higher than the Mg surface composition (1.1 and $1.1 \mathrm{wt} . \%)$. For the higher Mg loading (5 wt.\%) catalysts, different behavior can be observed depending on the parent zeolite. HZ25 shows an experimental surface Mg loading of $3.6 \mathrm{wt} . \%$, significantly lower than the bulk composition, 4.6 wt.\%, whilst the HZ40 zeolite has an experimental loading of $5.7 \mathrm{wt} . \%$, noticeably higher than the 
This is the peer reviewed version of the following article: ChemCatChem 2020, 12, 5236-5249, which has been published in final form at https://doi.org/10.1002/cctc.202000787. This article may be used for non-commercial purposes in accordance with Wiley Terms and Conditions for Use of Self-Archived Versions.

$\mathrm{Mg}$ bulk content, $5.0 \mathrm{wt} . \%$. Therefore, the $\mathrm{Si} / \mathrm{Al}$ ratio also seems to be important in determining the distribution of the $\mathrm{Mg}$ species. Whilst $\mathrm{MgO}$ at the near surface is preferred for the sample with the highest $\mathrm{Si} / \mathrm{Al}$ ratio, $\mathrm{MgO}$ also seems to be formed within the internal zeolite porosity for MgHZ25-5, in agreement with MAS NMR data. Additionally, XPS analyses show that the Si/Al surface ratio of both HZ25 and HZ40 decreases with increasing incorporation of Mg into the zeolite, as seen in Table 1. This may be attributed to the migration of the dislocated framework $\mathrm{Al}$, in the form of $\mathrm{Al}_{2} \mathrm{O}_{3}$, from the $\mathrm{Al}-\mathrm{O}$ tetrahedron to the surface, due to the electrostatic attraction induced by the $\left(\mathrm{Mg}^{2+} \mathrm{OH}^{-}\right)^{+}$cation, as proposed from MAS NMR data. This migration seems to be directly related to the amount of $\mathrm{Mg}$ deposited, as the atomic percentage of Al increases from 3.7 to 5.2 and 8.6 for the HZ25, MgHZ25-1 and MgHZ25-5 catalysts, respectively. The same trend is observed for the HZ40 catalysts where the atomic percentage of Al increases from 2.6 to 4.2 and 8.7, for the HZ40, MgHZ40-1 and MgHZ40-5 respectively. The migration of $\mathrm{Al}$ after $\mathrm{Mg}$ deposition is also supported by comparing the $\mathrm{Si} / \mathrm{Al}$ ratios, both on the surface (XPS results) and the bulk (EDX results), shown in Table 1. Si/Al ratios are 2 to 4 times lower on the surface than in the bulk, highlighting $\mathrm{Al}$ enrichment on the surface of all catalysts.


Figure 7. $\mathrm{NH}_{3}-\mathrm{TPD}$ profiles of the Mg-loaded hierarchical zeolites.

TPD-NH3 profiles were plotted in Figure 7, revealing some interesting properties. All catalysts exhibit two main TPD features. The first feature is an indication of weak adsorption sites that are associated with surface hydroxyl groups on the catalyst ${ }^{[14,31]}$, with desorption around $180-200{ }^{\circ} \mathrm{C}$. The second feature, is attributed to strong acidic sites, mainly Brønsted acidic sites ${ }^{[14,31]}$, with desorption maximum around 370 - 
This is the peer reviewed version of the following article: ChemCatChem 2020, 12, 5236-5249, which has been published in final form at https://doi.org/10.1002/cctc.202000787. This article may be used for non-commercial purposes in accordance with Wiley Terms and Conditions for Use of Self-Archived Versions.

$390{ }^{\circ} \mathrm{C}$. The peak temperature maxima and the amount of evolved $\mathrm{NH}_{3}\left(\mathrm{mmol} \mathrm{NH}_{3} / \mathrm{g}\right)$ are summarized in

Table S1. Mg-loaded zeolites exhibited lower quantities of ammonia evolution at low temperature, in comparison with acidic zeolites, likely to be related to the deposition of $\mathrm{Mg}$ amorphous species at the silanol groups. Acidic mesoporous zeolites were characterized by a significant amount of strong acidic sites, the HZ25 zeolite was the catalyst with the highest value $(0.051 \mathrm{mmol} / \mathrm{g})$. It can be observed that the mesoporous Mg-loaded zeolites displayed a drastically reduced amount of Brønsted acidic sites, except in the case of MgHZ40-1. These results agree with the results from MAS NMR and further strengthen the argument that the presence of $\left(\mathrm{Mg}^{2+} \mathrm{OH}^{-}\right)^{+}$at the specific exchange sites results in a decrease of the number of Brønsted acidic sites ${ }^{[17,26]}$.

Table 2. Number of Lewis and Brønsted sites $(\mu \mathrm{mol} / \mathrm{g})$ at 150,250 and $350{ }^{\circ} \mathrm{C}$ determined for some representative catalysts by Py-DRIFTS.

\begin{tabular}{|c|c|c|c|c|}
\hline $\mathrm{T}=150^{\circ} \mathrm{C}$ & HZ25 & MgHZ25-1 & HZ40 & MgHZ40-1 \\
\hline $\mathrm{C}_{\mathrm{L}}(\mu \mathrm{mol} / \mathrm{g})$ & 172 & 292 & 165 & 250 \\
\hline $\mathrm{C}_{\mathrm{B}}(\mu \mathrm{mol} / \mathrm{g})$ & 244 & 129 & 105 & 110 \\
\hline $\mathbf{C}_{\mathbf{B}} / \mathbf{C}_{\mathbf{L}}$ & 1.4 & 0.4 & 0.6 & 0.4 \\
\hline $\mathrm{T}=250^{\circ} \mathrm{C}$ & HZ25 & MgHZ25-1 & HZ40 & MgHZ40-1 \\
\hline $\mathrm{C}_{\mathrm{L}}(\mu \mathrm{mol} / \mathrm{g})$ & 147 & 156 & 107 & 168 \\
\hline $\mathrm{C}_{\mathrm{B}}(\mu \mathrm{mol} / \mathrm{g})$ & 223 & 80 & 88 & 83 \\
\hline $\mathbf{C}_{B} / \mathbf{C}_{\mathbf{L}}$ & 1.5 & 0.5 & 0.8 & 0.5 \\
\hline $\mathrm{T}=350^{\circ} \mathrm{C}$ & HZ25 & MgHZ25-1 & HZ40 & MgHZ40-1 \\
\hline$C_{L}(\mu \mathrm{mol} / \mathrm{g})$ & 102 & 151 & 91 & 105 \\
\hline $\mathrm{C}_{\mathrm{B}}(\mu \mathrm{mol} / \mathrm{g})$ & 123 & 78 & 73 & 59 \\
\hline $\mathbf{C}_{\mathbf{B}} / \mathbf{C}_{\mathbf{L}}$ & 1.2 & 0.5 & 0.8 & 0.6 \\
\hline
\end{tabular}

Table 2 summarizes the number of Lewis $\left(\mathrm{C}_{L}\right)$ and Brønsted acidic sites $\left(\mathrm{C}_{B}\right)$ of some key zeolite catalysts. In line with TPD-NH3 data, the $\mathrm{HZ} 25$ acidic zeolite was characterized by a marked quantity of $\mathrm{C}_{\mathrm{B}}$, having the highest value of $244 \mu \mathrm{mol} / \mathrm{g}$, about two-fold that found for HZ40 $(105 \mu \mathrm{mol} / \mathrm{g})$. On the contrary, $\mathrm{C}_{\mathrm{L}}$ were prevalent for HZ40, reaching the value of $165 \mu \mathrm{mol} / \mathrm{g}$. Therefore, whilst $\mathrm{C}_{B}$ prevails over $\mathrm{C}_{\mathrm{L}}$ for HZ25, the opposite is true for HZ40. As shown by MAS NMR, the presence of EFAL species in the latter could explain this feature. It is noticeable that $1 \mathrm{wt} . \% \mathrm{Mg}$ impregnation leads to a different distribution of the acidic sites. Whilst MgHZ25-1 displays a drastically reduced amount of $\mathrm{C}_{\mathrm{B}}$, these sites are 
This is the peer reviewed version of the following article: ChemCatChem 2020, 12, 5236-5249, which has been published in final form at https://doi.org/10.1002/cctc.202000787. This article may be used for non-commercial purposes in accordance with Wiley Terms and Conditions for Use of Self-Archived Versions.

maintained for the MgHZ40-1 zeolite, which is consistent with $\mathrm{NH}_{3}-\mathrm{TPD}$ data. Simultaneously, an increase in the number of $C_{L}$ is observed for both samples. In agreement with ${ }^{1} \mathrm{H}$ MAS NMR data, these results could be related to the formation of $\left(\mathrm{Mg}^{2+} \mathrm{OH}^{-}\right)^{+}$at the specific exchange sites together with EFAL species, which surprisingly results in a comparable amount in the number of $\mathrm{C}_{\mathrm{B}}$ and $\mathrm{C}_{\mathrm{L}}$ for both $1 \mathrm{wt} . \%$ loaded zeolites, regardless of their $\mathrm{Si} / \mathrm{Al}$ ratio.

Additionally, the strength of the different acidic sites can be evaluated, observing the evolution of $\mathrm{C}_{\mathrm{B}}$ and $\mathrm{C}_{\mathrm{L}}$ with the desorption temperature. We have assumed that the amount of strong acidic sites is associated with desorption at $350{ }^{\circ} \mathrm{C}$, intermediate ones are those acidic sites reported at $250{ }^{\circ} \mathrm{C}$ minus strong acidic sites, and weak acidic sites are from desorption at $150{ }^{\circ} \mathrm{C}$ minus those determined as intermediate and strong acidic sites. $1 \mathrm{wt} . \% \mathrm{Mg}$ impregnation led to a significant increase of strong $\mathrm{C}_{\mathrm{L}}$ and a reduction of $\mathrm{C}_{\mathrm{B}}$ for both acidic mesoporous zeolites, the effect is more apparent for MgHZ25-1, in agreement with MAS NMR and $\mathrm{NH}_{3}$-TPD data. In the case of the intermediate acid sites we can see a different pattern depending on the parent zeolite. Thus, the impregnation of HZ25 zeolite with Mg drastically reduces both the $\mathrm{C}_{\mathrm{L}}$ and $\mathrm{C}_{\mathrm{B}}$, while in the case of HZ40 there is a remarkable increase of Lewis sites accompanied of a slight increase of $\mathrm{C}_{\mathrm{B}}$. As previously mentioned, the formation of $\mathrm{C}_{\mathrm{L}}$, which are not strongly interacting with EFAL species, could be relevant in this series. Finally, a direct effect is again observed between the amount of weak acid sites and $1 \mathrm{wt} . \% \mathrm{Mg}$ impregnation. Although, both types of acidic sites are increased regardless of the parent zeolite, only MgHZ25-1 shows a marked increase in the amount of weak $\mathrm{C}_{\mathrm{L}}$, likely related to the formation of EFAL species. Summarizing, it can be concluded that despite MgHZ251 and MgHZ40-1 samples show a comparable acidity, the strength of the acidic sites seems to be notably different.

\section{Catalytic Upgrading Performance}

Reaction yields after the catalytic bio-oil upgrading process are summarized in Table 3. Firstly, the accurate quantification of the different product yields results in significant mass balance closure (95$99 \%$ ). Focusing on product yields, it is worth highlighting that, when using Mg-loaded catalysts, an increase ( $c a .10-12 \%$ ) of the total liquid fraction production is evident compared to the mesoporous acidic parent zeolites. Moreover, the organic fraction, considered the most valuable products, is also enhanced for all the Mg-loaded zeolites. Notably, organic fraction yields about $38 \%$ are achieved for those samples with low $\mathrm{Si} / \mathrm{Al}$ ratio (25). This result could be considered as one of the key factors for further designing a feasible process for bio-oil upgrading using this type of catalysts.

Regarding the remaining solid by-products, one of the main limitations during this upgrading process is the formation of char (and unreacted tar) at the top of the catalyst bed. This char formation inhibits the 
This is the peer reviewed version of the following article: ChemCatChem 2020, 12, 5236-5249, which has been published in final form at https://doi.org/10.1002/cctc.202000787. This article may be used for non-commercial purposes in accordance with Wiley Terms and Conditions for Use of Self-Archived Versions.

long-term continuous operation of the reactor, due to an excessive pressure drop, and also greatly decreases the liquid yield. In this sense, it is worth commenting that the afore-mentioned liquid and organic yields may be enhanced, minimizing this experimental limitation through a different advanced reactor type and configuration, such as commonly used trickled bed reactors ${ }^{[32]}$. This advanced configuration can increase the bio-oil residence time and enhance the overall heat transfer ${ }^{[33]}$. Another drawback associated with this process, and in particular with these types of catalysts, is coke deposition on the zeolite ${ }^{[34]}$. Coke deposition, mainly generated by complex reactions catalyzed by Brønsted acidic sites, such as oligomerization or poly-condensation, acts as an inhibitor, blocking the accessibility to the active sites of the zeolites, consequently diminishing the efficiency of the catalyst ${ }^{[18]}$. As shown in Table 3, the incorporation of $\mathrm{Mg}$ to the zeolite results in a slightly lower amount of coke formation, compared to the parent zeolites without $\mathrm{Mg}$, which is related to the reduction of Brønsted acidic sites after metalloading, as previously shown. These results, which are another key factor for the use of these materials, are in agreement with previous works where the same effect was observed for microporous ${ }^{[13]}$ and mesoporous ${ }^{[10]}$ metal-derived zeolites.

Table 3. Product yields (wt.\%) of the different fractions obtained after the catalytic upgrading of bio-oil over Mg-loaded ZSM-5 zeolites.

\begin{tabular}{|c|c|c|c|c|c|c|}
\hline Zeolite & $\begin{array}{c}\text { Organic } \\
\text { phase yield } \\
(\%)\end{array}$ & $\begin{array}{c}\text { Aqueous phase } \\
\text { yield } \\
(\%)\end{array}$ & $\begin{array}{l}\text { Solid } \\
\text { yield } \\
(\%)\end{array}$ & $\begin{array}{c}\text { Gas } \\
\text { yield } \\
(\%)\end{array}$ & $\begin{array}{c}\text { Balance } \\
(\%)\end{array}$ & $\begin{array}{c}\text { Coke in } \\
\text { zeolite }^{[\mathrm{a}]} \\
(\%)\end{array}$ \\
\hline HZ25 & 31 & 24 & 26 & 16 & 97 & 19 \\
\hline MgHZ25-1 & 38 & 22 & 18 & 20 & 98 & 17 \\
\hline MgHZ25-5 & 38 & 22 & 23 & 16 & 99 & 15 \\
\hline HZ40 & 19 & 26 & 25 & 25 & 95 & 17 \\
\hline MgHZ40-1 & 29 & 21 & 34 & 15 & 99 & 12 \\
\hline MgHZ40-5 & 26 & 24 & 28 & 18 & 96 & 15 \\
\hline
\end{tabular}

Table 4. Representative properties and analysis of the organic fraction of the upgraded bio-oil. For comparison, the main raw bio-oil properties have been also included. 
This is the peer reviewed version of the following article: ChemCatChem 2020, 12, 5236-5249, which has been published in final form at https://doi.org/10.1002/cctc.202000787. This article may be used for non-commercial purposes in accordance with Wiley Terms and Conditions for Use of Self-Archived Versions.

\begin{tabular}{|c|c|c|c|c|c|c|c|c|c|}
\hline \multirow[t]{2}{*}{ Zeolite } & \multicolumn{3}{|c|}{ Properties } & \multicolumn{4}{|c|}{ Ultimate analysis (wt.\%) } & \multirow{2}{*}{$\begin{array}{c}\% \\
\text { deox. }\end{array}$} & \multirow{2}{*}{$\begin{array}{c}\text { HHV } \\
(\mathrm{MJ} / \mathbf{k g})^{[\mathrm{cl}]}\end{array}$} \\
\hline & $\begin{array}{c}\mathrm{H}_{2} \mathrm{O} \\
\text { (wt.\%) }\end{array}$ & pH & $\begin{array}{c}\text { TAN }^{[a]} \\
(\mathrm{mgKOH} / \mathrm{g})\end{array}$ & $\mathbf{C}$ & $\mathbf{H}$ & $\mathbf{N}$ & $\mathbf{O}^{[\mathbf{b}]}$ & & \\
\hline Raw bio-oil & 5.9 & 5.2 & 40.4 & 57.8 & 7.4 & 0.5 & 34.3 & - & 21.3 \\
\hline HZ25 & 3.3 & 4.1 & 24 & 72.7 & 7.5 & 0.2 & 19.6 & 48.7 & 32.1 \\
\hline MgHZ25-1 & 3.5 & 4.0 & 13 & 76.8 & 7.6 & 0.2 & 15.4 & 56.9 & 34.3 \\
\hline MgHZ25-5 & 5.5 & 3.5 & 33 & 78.1 & 7.8 & 0.1 & 14.0 & 68.4 & 34.9 \\
\hline HZ40 & 3.2 & 3.7 & 17 & 75.4 & 7.7 & 0.1 & 16.8 & 47.6 & 34.1 \\
\hline MgHZ40-1 & 5.0 & 3.9 & 21 & 75.4 & 7.5 & 0.4 & 16.7 & 54.1 & 33.4 \\
\hline MgHZ40-5 & 5.1 & 4.0 & 29 & 76.1 & 7.7 & 0.2 & 16.0 & 57.0 & 33.9 \\
\hline
\end{tabular}

[a] TAN was determined according to ASTM D664 referred to petroleum products, biodiesel, and blends of biodiesel.

${ }^{[b]}$ Calculated by difference: (100\%-C \%-H\%-N\%).

[c] The heating value of both materials was measured experimentally with an IKA C-2000 calorimetric bomb according to UNE-EN ISO 18125:2018.

\section{Properties of the bio-oil}

The main target after any catalytic upgrading of a bio-oil process is to decrease the excessive initial oxygen content, whilst detrimental organic compounds, in terms of acidity and stability, are removed. Additionally, the large variety of oxygenated compounds, initially present in the bio-oil, should be converted into more desirable products, such as aromatics. This new chemical composition can give the bio-oil properties that need to be evaluated for potential application as fuel or source of chemicals. The main properties of the bio-oil are summarized in Table 4. Deoxygenation rate was calculated from the oxygen content, determined by elemental analyses, as the difference from that of the initial bio-oil (discounting the oxygen accounted for in water). It can be highlighted that elemental analyses of the upgraded bio-oils showed an outstanding reduction of oxygen content for HZ25 (close to $50 \%$ ), which increased further for Mg-loaded zeolites. The highest degree of deoxygenation is obtained for MgHZ255 zeolite, reaching a significant value of deoxygenation rate, $68 \%$. This is a very notable result, which is an increased deoxygenation rate of $30 \%$, compared to acidic mesoporous counterpart. Likewise, 
This is the peer reviewed version of the following article: ChemCatChem 2020, 12, 5236-5249, which has been published in final form at https://doi.org/10.1002/cctc.202000787. This article may be used for non-commercial purposes in accordance with Wiley Terms and Conditions for Use of Self-Archived Versions.

deoxygenation rates are also increased for the other Mg-loaded catalysts, and were always $15 \%$ higher than the parent acidic zeolites. These findings are also in agreement with previous work, where a pronounced deoxygenation rate was achieved when non-optimized $1 \mathrm{wt} \%$ Mg-loaded ZSM-5 zeolite $(\mathrm{Si} / \mathrm{Al}=40)$ prepared by wet impregnation was screened together with other metal-impregnated mesoporous zeolites $\left(\mathrm{Ni}, \mathrm{Sn}\right.$ and $\mathrm{Cu}$ ) for the upgrading process ${ }^{[18]}$.

Another important key parameter that causes some of the main problems associated with bio-oils is their acidity. This parameter, which is related to the potential of the liquid to cause corrosion, can be quantified by means of $\mathrm{pH}$ and TAN (Total Acid Number). All the mesoporous zeolite-derived catalysts show a reduced TAN, compared to that obtained for the initial raw pyrolytic bio-oil. Specifically, MgHZ25-1 displays the lowest TAN (12.6 mg KOH/gbio-oil). Surprisingly, $\mathrm{pH}$ values remain in the same range (3.54) still evidencing the acidic nature of these bio-oils ${ }^{[35]}$. Additionally, the upgrading process entails a noteworthy enhancement of the HHV (Higher Heating Value). These values increase to 34-35 MJ/kg, significantly improving the HHV compared to the initial bio-oil (21.3 MJ/kg). Interestingly, $5 \mathrm{wt} . \% \mathrm{Mg}$ loaded zeolites with $\mathrm{Si} / \mathrm{Al}=25$ showed the highest value $(35 \mathrm{MJ} / \mathrm{kg})$, which is higher than that previously obtained for non-optimized $1 \mathrm{wt} . \%$ Mg-loaded ZSM-5 zeolite $(\mathrm{Si} / \mathrm{Al}=40)$ prepared by wet impregnation $(32 \mathrm{MJ} / \mathrm{kg}){ }^{[11]}$

GC/MS analysis was used to identify the wide variety of components in the organic bio-oil fraction. More than 100 different compounds were detected (Table S2 and Figure S3, Supporting Information). The composition of the bio-oil is assessed by a semi-quantitative approach, determining the relative area percentage for all the identified constituents, which were classified in different groups (phenols, acids, aldehydes, furans, cyclic ketones, cyclic hydrocarbons, aromatic hydrocarbons, polyaromatic hydrocarbons, and esters). The relative amount of each group was calculated based on the relative peak area of each component of the group (Table S2), the total liquid yield and the organic fraction yield. Accordingly, each group is expressed as percentage per gram of raw bio-oil feed ( $\%$ area/100gbio-oil feed), since this approach enabled the most accurate form of qualitative comparison.

Table 5. GC/MS Semi-Quantitative Analysis of Upgraded Bio-Oil (\% area/100g bio-oil feed). For comparison, GC/MS composition of raw bio-oil (area \%) has been also included.

\begin{tabular}{|c|c|c|c|c|c|c|c|c|c|c|}
\hline Zeolite & $\frac{\mathscr{c}}{e}$ & $\frac{e_{0}^{0}}{\frac{0}{0}}$ & 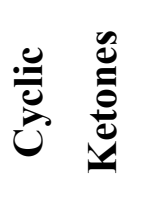 & $\frac{0}{0}$ & $\underset{\Xi}{E}$ & $\frac{n}{0}$ & 导 & n &  & 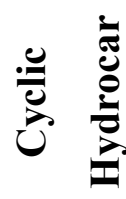 \\
\hline Raw bio-oil & 0.4 & 0.4 & 1.8 & 10.9 & 1.0 & 54.2 & & 2.8 & 26.4 & 2.1 \\
\hline$\overline{\text { HZ25 }}$ & 0.3 & 0.3 & 1.3 & 5.2 & 2.6 & 39.9 & & 23.5 & 23.9 & 2.9 \\
\hline
\end{tabular}


This is the peer reviewed version of the following article: ChemCatChem 2020, 12, 5236-5249, which has been published in final form at https://doi.org/10.1002/cctc.202000787. This article may be used for non-commercial purposes in accordance with Wiley Terms and Conditions for Use of Self-Archived Versions.

\begin{tabular}{llllllllll}
\hline MgHZ25-1 & 0.3 & 0.3 & 1.0 & 5.8 & 1.6 & 26.6 & 31.1 & 29.8 & 3.5 \\
MgHZ25-5 & 0.3 & 0.5 & 1.9 & 5.3 & 1.9 & 45.5 & 12.8 & 28.8 & 3.0 \\
HZ40 & 0.0 & 0.5 & 1.0 & 2.6 & 1.6 & 37.2 & 30.9 & 20.4 & 5.8 \\
MgHZ40-1 & 0.0 & 0.5 & 2.1 & 3.6 & 2.1 & 46.4 & 19.8 & 21.9 & 3.6 \\
MgHZ40-5 & 0.5 & 0.5 & 2.1 & 5.3 & 2.1 & 46.3 & 21.1 & 18.4 & 3.7
\end{tabular}

The semi-quantitative approach showing the relative area percentage for the main components is shown in Table 5. For a better comparison, the results obtained for the non-loaded parent mesoporous zeolites are also included. The major components of the raw bio-oil are phenols, aldehydes, ketones, acids, polyaromatics, and furans. Phenols, furans, and oxygen-containing compounds, such as carboxylic acids and aldehydes, are considered undesirable fractions for energy production, whereas linear, cyclic and aromatic hydrocarbons are the most desirable fractions. Additionally, it must be pointed out that the transformation of acids into ester compounds, as already performed for biodiesel production from edible oils, can be considered as another promising strategy to obtain renewable fuels due to their neutral character (less corrosive) and high stability under storage ${ }^{[36]}$. Similarly, the production of ketones, from either acids or aldehydes by ketonization reactions at basic sites, has also been proposed in the literature as a potential alternative for bio-oil upgrading and stabilization ${ }^{[37]}$.

Compared to parent acidic zeolites where we have previously demonstrated that the deoxygenation mechanism is associated with the formation of aromatic compounds at Bronsted acidic sites through decarbonylation reactions of phenolic compounds ${ }^{[10 b]}$, extra deoxygenation routes seem to be accounted for the Mg-loaded mesoporous zeolites. Accordingly, it can be observed that the aforementioned reduction in the oxygen content of the upgraded bio-oil using Mg-loaded catalysts compared to the parent counterparts (see Table 4) is not mirrored in a lower production of undesired oxygenated compounds, also leading to a lower formation of both aromatics and cyclic hydrocarbons, except in the particular case of MgHZ25-1. Thus, the increase in the deoxygenation rate could be related to the formation of new oxygen-containing compounds with lower oxygen content ${ }^{[11]}$. Accordingly, several oxygen-rich compounds, such as guaiacol $\left(\mathrm{C}_{7} \mathrm{H}_{8} \mathrm{O}_{2}\right), 2$,3-Dimethylhydroquinone $\left(\mathrm{C}_{8} \mathrm{H}_{10} \mathrm{O}_{2}\right)$ and phenol 2-methoxy-4propyl- $\left(\mathrm{C}_{10} \mathrm{H}_{14} \mathrm{O}_{2}\right)$, are significantly reduced (Table $\mathrm{S} 2$, Supporting Information).

Nonetheless, it should be remarked that the formation of aromatics from phenolic compounds should be still considered as a relevant deoxygenation route for all these materials (as shown later), since only phenolic compounds were obviously upgraded in the raw bio-oil (initial phenolic content $=54.2 \%$ area), whilst the other oxygenated components were only slightly modified. However, the deoxygenation process for Mg-loaded samples also seems to proceed through decarboxylation reactions rather than mainly decarbonylation reactions associated with the parent mesoporous acidic zeolites ${ }^{[10 b]}$. This 
This is the peer reviewed version of the following article: ChemCatChem 2020, 12, 5236-5249, which has been published in final form at https://doi.org/10.1002/cctc.202000787. This article may be used for non-commercial purposes in accordance with Wiley Terms and Conditions for Use of Self-Archived Versions.

statement can be confirmed by following the $\mathrm{CO}_{2}$ evolution in the non-condensable gas fraction for the different Mg-loaded catalysts. Although more samples would be needed to reach a reliable correlation (see Figure S4), it can be tentatively proposed that there could be a strong relationship between deoxygenation rate and $\mathrm{CO}_{2}$ production, since the highest $\mathrm{CO}_{2}$ concentration is observed for those samples with the highest deoxygenation rate, MgHZ25-5 and MgHZ40-5, and vice versa, see Table 6. For these samples, it can be also seen that the relative amount of ketones and esters slightly increases compared to the parent counterparts, which is in line with previous work using a non-optimized $1 \mathrm{wt} . \%$ Mg-loaded ZSM-5 zeolite $(\mathrm{Si} / \mathrm{Al}=40)$ prepared by wet impregnation, where the higher deoxygenation rate compared to the parent acidic zeolite was linked to the enhancement of decarboxylation reactions, such as esterification of acids and alcohols or ketonization of acids with aldehydes at $\mathrm{Mg}$ sites ${ }^{[11,14]}$.

Table 6. Gas composition after catalytic upgrading of bio-oil over Mg-Loaded Zeolites (g/100 gbio-oil feed). $\mathrm{C}_{4}$ : hydrocarbons with 4 carbon atoms.

\begin{tabular}{lcccccccc}
\hline \multirow{2}{*}{ Zeolite } & \multicolumn{7}{c}{$\mathrm{g} / 100 \mathrm{~g}$ bio-oil feed } \\
\cline { 2 - 8 } & $\mathbf{H}_{\mathbf{2}}$ & $\mathbf{C O}$ & $\mathbf{C O}_{\mathbf{2}}$ & $\mathbf{C H}_{\mathbf{4}}$ & $\mathbf{C}_{\mathbf{2}} \mathbf{H}_{\mathbf{6}}$ & $\mathbf{C}_{\mathbf{2}} \mathbf{H}_{\mathbf{4}}$ & $\mathbf{C}_{\mathbf{3}} \mathbf{H}_{\mathbf{8}}$ & $\mathbf{C}_{\mathbf{4}}$ \\
\hline HZ25 & 0.02 & 6.6 & 4.2 & 1.4 & 0.3 & 0.7 & 2.3 & 0.1 \\
MgHZ25-1 & 0.02 & 8.1 & 5.8 & 1.4 & 0.3 & 1.1 & 2.9 & 0.2 \\
MgHZ25-5 & 0.02 & 6.0 & 6.7 & 1.0 & 1.0 & 0.05 & 1.4 & 0.1 \\
HZ40 & 0.05 & 8.4 & 5.5 & 3.0 & 2.3 & 1.2 & 3.6 & 0.5 \\
MgHZ40-1 & 0.02 & 5.9 & 5.0 & 1.8 & 0.8 & 0.1 & 1.4 & 0.04 \\
MgHZ40-5 & 0.03 & 6.4 & 6.1 & 1.6 & 1.2 & 0.1 & 2.6 & 0.1 \\
\hline
\end{tabular}

Consistent with characterization data, the upgrading mechanism for Mg-loaded mesoporous zeolites could be also related to the presence of $\mathrm{Mg}$ species, acting as active sites during the deoxygenation mechanism. To support this hypothesis, we can clearly observe that Mg-loading significantly increases both, deoxygenation rates and formation of cyclic ketones, except for MgHZ25-1, where cyclic ketones were decreased due to an extra deoxygenation route (shown later). We can also observe that MgHZ25-5 and MgHZ40-5 (catalysts with the highest Mg content), lead to the highest deoxygenation rate for each series, along with the greatest formation of cyclic ketones, $\mathrm{CO}_{2}$ and $\mathrm{H}_{2} \mathrm{O}$. However, $\mathrm{Mg}$ species have different roles when comparing the performance of these two samples. On one hand, MgHZ40-5, which is the catalyst with the highest Mg loading (surface and bulk), produced the highest number of cyclic ketones (and esters), but led to lower deoxygenation rate and $\mathrm{CO}_{2}$ formation than MgHZ25-5. Since $\left(\mathrm{Mg}^{2+} \mathrm{OH}^{-}\right)^{+}$species at exchanged positions are significantly higher in MgHZ40-5, it can be tentatively 
This is the peer reviewed version of the following article: ChemCatChem 2020, 12, 5236-5249, which has been published in final form at https://doi.org/10.1002/cctc.202000787. This article may be used for non-commercial purposes in accordance with Wiley Terms and Conditions for Use of Self-Archived Versions.

proposed that these sites are critical for the promotion of ketonization (and esterification) reactions. On the other hand, the number and distribution of $\mathrm{MgO}$ species could also have a key role on the deoxygenation mechanism, since the best deoxygenation rate is achieved for MgHZ25-5, where the presence of a significant amount of $\mathrm{MgO}$ species within the internal porosity is demonstrated by XPS and NMR analyses. Accordingly, we can assume that $\mathrm{MgO}$ species seem to promote the decarboxylation of phenols towards the formation of phenolic compounds with lower oxygen content. These findings are consistent with the work conducted by Stefanidis et al. ${ }^{[38]}$, where several $\mathrm{MgO}$ catalysts were used for the upgrading of bio-oil in a bench-scale fixed-bed reactor. In this work, an increase in the $\mathrm{CO}_{2}$ yield, together with ketones formation, were also achieved when compared with acidic zeolites. The presence of basic $\mathrm{Mg}$-derived species was linked to the enhancement of $\mathrm{CO}_{2}$ production and thus, the efficient promotion of bio-oil deoxygenation through decarboxylation reactions.

Additionally, the formation of aromatic compounds as key chemicals for industry was carefully evaluated. Interestingly, it should be highlighted that the production of light aromatic compounds is only improved in the case of the MgHZ25-1 catalyst. The total aromatics content including single ring and polyaromatics reaches values of 60,9\% (bio-oil feed basis), significantly higher in comparison with the parent mesoporous HZ25, $47.4 \%$. For the other Mg-loaded zeolites, the catalytic upgrading decreased the aromatic yield compared to the acidic counterparts. Figure S5 shows that there is a linear relationship between total aromatics formation (aromatics + polyaromatics) and phenol reduction over all catalysts. This suggests that the preferential route of aromatics production over these catalysts is carried out through phenol deoxygenation. We have recently observed ${ }^{[39]}$ that Brønsted acidic sites at the mesopore surface on hierarchical acidic ZSM-5 zeolites play a fundamental role in aromatization reactions and are critical for deoxygenation of phenolic compounds in the pyrolysis vapor, thus contributing to protolytic cracking and olefin oligomerization for the formation of aromatic hydrocarbons. Additionally, it was demonstrated that the increased formation of aromatics over hierarchical zeolites could be attributed to the preferential occurrence of decarbonylation reactions, in contrast to the prevalence of dehydration reactions observed over the bulk materials. The results achieved in the present work also show that the formation of aromatic hydrocarbons is directly correlated to the $\mathrm{CO}$ released during the upgrading process, as can be evidenced in Figure S5, suggesting that phenol decarbonylation into desired aromatics is the main mechanism to promote aromatic production. 
This is the peer reviewed version of the following article: ChemCatChem 2020, 12, 5236-5249, which has been published in final form at https://doi.org/10.1002/cctc.202000787. This article may be used for non-commercial purposes in accordance with Wiley Terms and Conditions for Use of Self-Archived Versions.

It should be commented that although there is a lack of correlation between the evolution of Brønsted acidic sites observed by Py-FTIR and the aromatic yield, a suitable distribution of these acidic sites over the external surface of the catalyst together with a slightly higher mesoporosity development ${ }^{[39]}$ could explain the fact that MgHZ25-1 is the sample leading to the highest aromatic yield. Nonetheless, it is worth mentioning that another potential route for the production of aromatics over Mg-loaded mesoporous ZSM-5 catalysts can be related to the promotion of aldol condensation reactions at $\mathrm{Mg}$ Lewis sites and further dehydration at the Brønsted acidic sites, that is, consecutively converting ketones into aldols and, then, into aromatics ${ }^{[40]}$. This approach may also account for the MgHZ25-1 performance, since a reduction in ketones production is accompanied by the most pronounced increase of the aromatic yield. This suggests that this reaction could be an additional upgrading mechanism for bio-oil deoxygenation using this catalyst. As previously mentioned, this zeolite likely has a significant number of Brønsted acidic sites at the external surface, together with a relevant number of strong Lewis acidic sites in the internal zeolite channels created by the interaction between $\left(\mathrm{Mg}^{2+} \mathrm{OH}^{-}\right)^{+}$and EFAL species, as shown by MAS NMR. Additionally, it should be highlighted that the incorporation of these Mg species into the internal extra framework exchange positions does not lead to a blockage of the mesoporosity, which is indeed slightly increased due to a dealumination process. An open mesoporosity can enhance the diffusion of bulky oxygenates into the internal zeolite channels where ketonization reactions seem to be favored. Subsequently, aromatic formation can be accomplished at the Brønsted acidic sites remaining on the external zeolite surface, through aldol condensation and dehydration reactions, as ketonization products diffuse out of the zeolite framework.

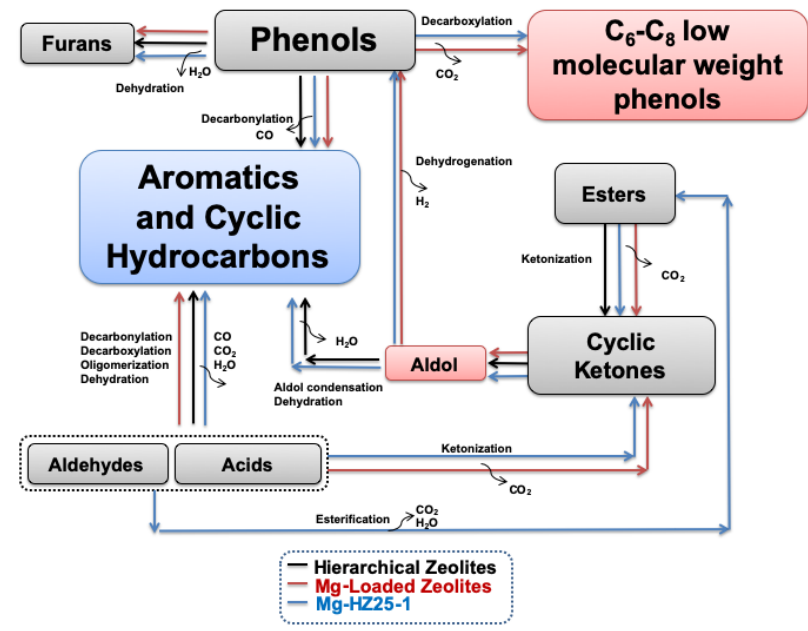

Figure 8. Predominant routes represented as a reaction network (Adapted from ${ }^{[10 \mathrm{~b}]}$ ) for the catalytic upgrading of bio-oil to aromatic-rich fraction bio-oil over acidic hierarchical zeolites and $\mathrm{Mg}$-loaded hierarchical zeolites. Black: Mesoporous HZSM-5 zeolites; Blue: Mg-Loaded zeolites; Red: MgHZ25-1 
This is the peer reviewed version of the following article: ChemCatChem 2020, 12, 5236-5249, which has been published in final form at https://doi.org/10.1002/cctc.202000787. This article may be used for non-commercial purposes in accordance with Wiley Terms and Conditions for Use of Self-Archived Versions.

The main deoxygenation and aromatization routes suggested in this manuscript have been summarized in Figure 8, which is based on a hydrocarbon pool mechanism previously reported for bio-oil upgrading using mesoporous acidic zeolites ${ }^{[10 b, 41]}$. Mesoporous zeolites allow the oxygenated intermediates to diffuse into the more accessible pore channels, where a series of reactions take place, including decarboxylation, decarbonylation, oligomerization and dehydration. In previous work, we demonstrated that different oxygen containing compounds can be converted into monocyclic and polycyclic aromatics, as well as into cyclic hydrocarbons, over the Brønsted acidic sites situated at the external surface. In particular, decarbonylation of phenols to aromatics was evident as a prevalent mechanism as it is also observed for catalysts herein (see Figure S4). Mg-loaded zeolites also seem to promote additional deoxygenation routes due to the presence of $\mathrm{Mg}$ species. Whilst $\mathrm{MgO}$ nanoparticles seem to be involved in the decarboxylation of oxygen-rich phenolic components into organic compounds with lower oxygen content, this being a key upgrading mechanism towards bio-oils with lower oxygen content, ketonization and esterification reactions at extraframework positions, acting as Lewis active sites, ${ }^{[11,14]}$ are postulated as extra deoxygenation routes for these catalysts. Finally, it cannot be ruled out that the presence of highly accessible strong Lewis acidic sites in the internal zeolite channels of MgHZ25-1, which are created by the interaction between $\left(\mathrm{Mg}^{2+} \mathrm{OH}^{-}\right)^{+}$and EFAL species, jointly with Brønsted acidic sites at the external surface, could also promote the formation of aromatics through ketonization and further aldol

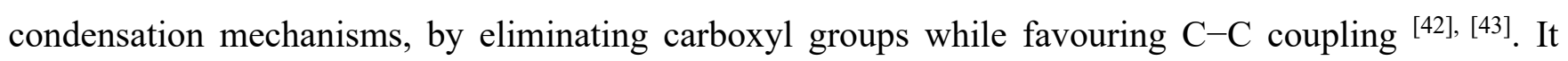
should be commented that although the relative importance of the latter upgrading route for the production of aromatics is not particularly relevant for the raw bio-oil upgraded in this manuscript, due to its marginal content in acids and aldehydes content, the presence of these components could be higher for other biooils obtained under different reaction conditions ${ }^{[44]}$, likely enhancing the role of this upgrading route towards the formation of aromatics.

Therefore, it can be concluded that a suitable concentration, distribution, strength and accessibility of the acidic sites are fundamental parameters in the development of catalysts for the production of upgraded bio-fuels from lignocellulosic pyrolytic bio-oils using Mg-loaded zeolites. The most promising catalyst for the production of highly deoxygenated bio-oils is a mesoporous $5 \mathrm{wt} . \% \mathrm{Mg}$-loaded zeolite obtained from commercial ZSM-5 (Si/Al=25). However, a 1 wt.\% Mg-loaded zeolite obtained from commercial ZSM-5 ( $\mathrm{Si} / \mathrm{Al}=25)$ should be selected if the production of aromatics is the final objective, even improving the results reached by acidic ZSM-5 zeolites.

At this point, it should be noted that although regeneration cycles were not accomplished, the phase purity and crystallinity of the used zeolites samples were verified by XRD. XRD patterns of used MgHZ25-1 and MgHZ25-5 zeolites are presented in Figure 9. The analysis confirms, that whilst MFI structure and phase purity of the catalysts are unmodified after application, sample crystallinity seems to be decreased 
This is the peer reviewed version of the following article: Chem CatChem 2020, 12, 5236-5249, which has been published in final form at https://doi.org/10.1002/cctc.202000787. This article may be used for non-commercial purposes in accordance with Wiley Terms and Conditions for Use of Self-Archived Versions.

compared to the fresh zeolites. Therefore, further studies assessing the stability of the Mg-loaded zeolites under reaction conditions and during cyclic operation need to be carried out. In this sense, it would be very interesting to compare the stability performance of these materials to that previously reported for mesoporous acidic ZSM-5 zeolites ${ }^{[10 b]}$, where a decrease in the yield to aromatics was observed during the first cycle, before being stable in subsequent cycles. This trend was linked to a reduction in the amount of Brønsted acid sites within the developed mesoporosity, as these were the species responsible for the production of aromatics. Therefore, a further detailed study showing the evolution of the different active sites identified in this manuscript for Mg-loaded zeolites, such as $\mathrm{MgO}$, strong Lewis acidic sites associated with $\left(\mathrm{Mg}^{2+} \mathrm{OH}^{-}\right)^{+}$species interacting with EFAL and Brønsted acidic sites at the external surface, would be of high interest. However, we really think that this study is beyond the scope of the current manuscript where very interesting insights into the production of upgraded biofuels using $\mathrm{Mg}$ loaded zeolites are already reported.
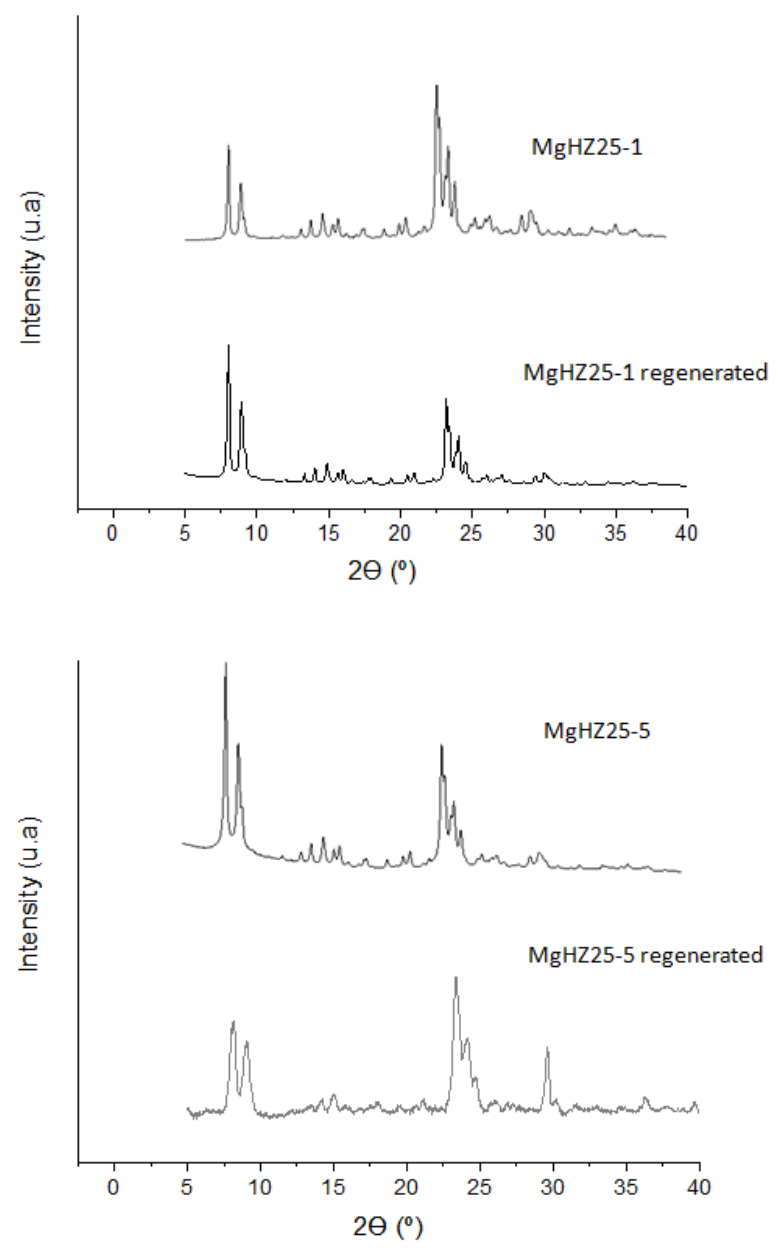

Figure 9. XRD patterns of the mesoporous MgHZ25-1 and MgHZ25-5 after their use in the catalytic upgrading of bio-oil. 
This is the peer reviewed version of the following article: ChemCatChem 2020, 12, 5236-5249, which has been published in final form at https://doi.org/10.1002/cctc.202000787. This article may be used for non-commercial purposes in accordance with Wiley Terms and Conditions for Use of Self-Archived Versions.

\section{Conclusion}

New insight into the deoxygenation of bio-oils using Mg-loaded mesoporous zeolites, synthetized from commercial ZSM-5 with two distinctive $\mathrm{Si} / \mathrm{Al}$ ratios (25 and 40), has been obtained. Incipient wetness impregnation with two different $\mathrm{Mg}$ loadings (1 and $5 \mathrm{wt} . \%$ ) gave an enhancement in both the yield of upgraded bio-oil and deoxygenation rates, when compared to the parent acidic mesoporous zeolites. Additionally, deoxygenation rates were markedly higher than those previously reported for a benchmark 1 wt.\% Mg mesoporous zeolite obtained from commercial ZSM-5 (42\%, for ZSM-5 Si/Al=40). ${ }^{[11]}$ In the case of a 5 wt.\% Mg-loaded zeolite synthesized from commercial ZSM-5 ( $\mathrm{Si} / \mathrm{Al}=25)$ deoxygenation around $70 \%$ was achieved. The quantity and distribution of $\mathrm{Mg}$ species has a key role on the deoxygenation mechanism, since the presence of accessible $\mathrm{MgO}$ species within the internal porosity is highly beneficial. Noticeably, a mesoporous zeolite obtained from commercial ZSM-5 (Si/Al=25), impregnated with 1 wt.\% Mg, led to the highest yield to light aromatics together with high deoxygenation rates. The formation of strong Lewis acidic sites in the internal zeolite channels, created by the interaction between $\left(\mathrm{Mg}^{2+} \mathrm{OH}^{-}\right)^{+}$at specific exchange sites and EFAL species, whilst significantly preserving Brønsted acidic sites at the external surface, produced a catalyst for which the production of light aromatic compounds was enhanced compared to counterpart acidic zeolites.

\section{Experimental Section}

\section{Raw bio-oil}

As initial feedstock, a real lignocellulosic-derived catalytic pyrolysis bio-oil was selected to carry out the experiments. This bio-oil was produced from a pilot plant of $100 \mathrm{kWth}$ of nominal capacity for woody biomass fitted with an auger pilot reactor. The reactor operation conditions and performance of the global process are described in previous work ${ }^{[7 \mathrm{c}, 7 \mathrm{~d}, 45]}$. Briefly, a catalytic pyrolysis experiment was carried out at $450{ }^{\circ} \mathrm{C}$ using $\mathrm{N}_{2}$ as a carrier gas, feeding $2 \mathrm{~kg} / \mathrm{h}$ of biomass (pine wood pellets) at atmospheric pressure and using $\mathrm{CaO}$ as an in situ catalyst ${ }^{[46]}$. The organic layer of the liquid was easily separated by a centrifugation-decantation method (1500 rpm for $30 \mathrm{~min}$ ). This organic phase was selected and referred to as the raw bio-oil. The main raw bio-oil properties were as follows: water content, $5.9 \mathrm{wt} . \%$; total acid number (TAN), $40.4 \mathrm{mg} \mathrm{KOH} / \mathrm{g}$ bio-oil; $\mathrm{pH} 5.2 ; \mathrm{HHV}, 21.3 \mathrm{MJ} / \mathrm{kg}$; ultimate analysis (wt \%), 57.8 \% C, $7.4 \% \mathrm{H}, 0.5 \% \mathrm{~N}, 34.3 \% \mathrm{O}$; GC/MS composition (area \%), $54.2 \%$ phenols, $0.36 \%$ acids, $0.42 \%$ 
This is the peer reviewed version of the following article: ChemCatChem 2020, 12, 5236-5249, which has been published in final form at https://doi.org/10.1002/cctc.202000787. This article may be used for non-commercial purposes in accordance with Wiley Terms and Conditions for Use of Self-Archived Versions.

aldehydes, $1.01 \%$ furans, $1.77 \%$ cyclic ketones, $10.92 \%$ esters, $2.13 \%$ cyclic hydrocarbons, $2.83 \%$ aromatics and $26.36 \%$ polyaromatic hydrocarbons.

\section{Catalysts}

\section{Catalyst Preparation}

A commercial ZSM-5 zeolite (CBV 8014, Zeolyst International, nominal Si/Al ratio $=25$ and 40, $\mathrm{NH}_{4}-$ form) was converted to the protonic form by calcination at $450{ }^{\circ} \mathrm{C}$ for $6 \mathrm{~h}$ in static air (ramp rate $=$ $\left.5{ }^{\circ} \mathrm{C} / \mathrm{min}\right)$. Hierarchical ZSM-5 was prepared by desilication in stirred aqueous $\mathrm{NaOH}$ ( $\geq 98 \%$ SigmaAldrich) solution $\left(0.2 \mathrm{M}, 65^{\circ} \mathrm{C}, 30 \mathrm{~min}, 30 \mathrm{~cm}^{3} / \mathrm{g}_{\text {zeolite }}\right){ }^{[47]}$. The slurries resulting from each step were quenched in ice-water, filtered and the isolated solids were washed extensively with deionized water and dried at $105{ }^{\circ} \mathrm{C}$ for $13 \mathrm{~h}$. The hierarchical sample was converted into the $\mathrm{H}$-form by two consecutive ion exchanges in aqueous ammonium nitrate (99.8\% Fisher Scientific) solution (1 M, $80{ }^{\circ} \mathrm{C}, 24 \mathrm{~h}, 12$ $\mathrm{cm}^{3} / \mathrm{g}_{\text {zeolite}}$ ) followed by calcination as described above. The loading of magnesium (nominal charges of 1 and 5 wt.\%) was carried out by incipient wetness impregnation, treating the zeolites (3 g) with $\mathrm{Mg}\left(\mathrm{NO}_{3}\right)_{2}$, according to the method used by other authors ${ }^{[13]}$. Impregnated samples were heat treated at $450^{\circ} \mathrm{C}$ in air. Samples are coded as HZ25 and HZ40 for acidic hierarchical zeolites and MgHZ25-X or MgHZ40-X for acidic hierarchical and cation-loaded hierarchical zeolites, where $\mathrm{X}$ corresponds to the nominal loading of $\mathrm{Mg}$.

\section{Characterization}

The characterization of the catalysts was completed by X-ray diffraction (XRD), $\mathrm{N}_{2}$ physisorption, temperature programmed desorption of ammonia ( $\left.\mathrm{NH}_{3}-\mathrm{TPD}\right)$, pyridine- diffuse reflectance infrared Fourier transform spectroscopy (Py-DRIFTS), transmission electron microscopy (TEM), solid-state MAS NMR and X-ray photoelectron spectroscopy (XPS). X-ray diffraction patterns were measured with a Bruker D8 Advance series II diffractometer using monochromatic $\mathrm{Cu} K \alpha$ radiation $(\lambda=0.1541 \mathrm{~nm})$. Data were collected in the $2 \theta$ range from $3^{\circ}$ to $40^{\circ}$ using a scanning rate of $1^{\circ} / \mathrm{min}$. $\mathrm{N}_{2}$ physisorption was performed by a Quantachrome Autosorb 1 gas adsorption analyzer. Prior to the adsorption measurements, the samples were outgassed in situ under vacuum ( 4 mbar) at $250{ }^{\circ} \mathrm{C}$ for $4 \mathrm{~h}$. $\mathrm{NH}_{3}-\mathrm{TPD}$ was measured by using a Micromeritics Pulse Chemisorb 2700 instrument equipped with a TCD. The catalysts $(0.2 \mathrm{~g})$ were degassed under an Ar flow at $500{ }^{\circ} \mathrm{C}$ for $6 \mathrm{~h}$ followed by saturation at $150{ }^{\circ} \mathrm{C}$ using a $30 \mathrm{~cm}^{3} \mathrm{STP} / \mathrm{min}$ 
This is the peer reviewed version of the following article: ChemCatChem 2020, 12, 5236-5249, which has been published in final form at https://doi.org/10.1002/cctc.202000787. This article may be used for non-commercial purposes in accordance with Wiley Terms and Conditions for Use of Self-Archived Versions.

flow of $5 \% \mathrm{v} / \mathrm{v} \mathrm{NH} 3$ in Ar. The gas mixture was then switched back to Ar and the sample was purged at $125^{\circ} \mathrm{C}$ for $30 \mathrm{~min}$. $\mathrm{NH}_{3}$-TPD profiles were subsequently recorded under $30 \mathrm{~cm}^{3} \mathrm{STP} / \mathrm{min}$ He flow, from $50{ }^{\circ} \mathrm{C}$ to $600{ }^{\circ} \mathrm{C}$ using a heating rate of $5{ }^{\circ} \mathrm{C} / \mathrm{min}$. Fourier transform infrared spectroscopy (FTIR) of adsorbed pyridine was conducted in a Bruker IFS 66 spectrometer $\left(650-4000 \mathrm{~cm}^{-1}, 2 \mathrm{~cm}^{-1}\right.$ optical resolution, co-addition of 32 scans). Self-supporting wafers of catalyst ( 5 ton $\mathrm{cm}^{-1}, 30 \mathrm{mg}, 1 \mathrm{~cm}^{2}$ ) were degassed under vacuum $\left(10^{-3} \mathrm{mbar}\right)$ for $4 \mathrm{~h}$ at $420^{\circ} \mathrm{C}$, prior to adsorbing pyridine at room temperature. Gaseous and weakly adsorbed molecules were subsequently removed by evacuation at $150{ }^{\circ} \mathrm{C}$ for $60 \mathrm{~min}$. Then, the sample was heated under a $\mathrm{N}_{2}$ flow to different desorption temperatures $\left(150,250\right.$ and $\left.350{ }^{\circ} \mathrm{C}\right)$. Spectra were collected for each material at these temperatures. The total concentrations of Brønsted and Lewis acid sites were calculated from the band area of adsorbed pyridine at 1545 and $1454 \mathrm{~cm}^{-1}$, using a

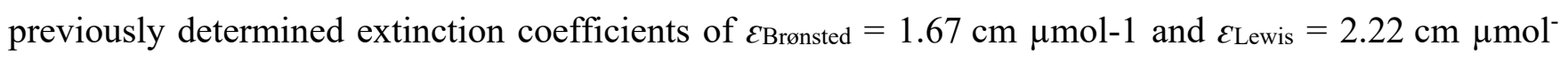
$1[48]$.

Morphological and structural characterization of the samples were performed by transmission electron microscopy (TEM) and high resolution TEM (HRTEM), by using a FEI Field Emission Gun (FEG) TECNAI G2 F20 S-TWIN microscope operated at $200 \mathrm{kV}$. The composition distribution was determined by using Energy Dispersive X-ray spectroscopy (EDX)-mapping in a TEM microscope. The synthesized powder samples were treated by sonicating in absolute ethanol for a few minutes, and a drop of the resulting suspension was deposited onto a holey-carbon film supported on a copper grid, which was subsequently dried.

Solid-state ${ }^{1} \mathrm{H},{ }^{27} \mathrm{Al}$ and ${ }^{29} \mathrm{Si}$ MAS NMR spectra were recorded on a Bruker AVANCE 400WB magnet and a ASCEND III HD Spectrometer, with a magnetic field strength of $9.4 \mathrm{~T}$. The resonance frequency used for each nuclei was, ${ }^{1} \mathrm{H} 400 \mathrm{MHz},{ }^{27} \mathrm{Al} 104.23 \mathrm{MHz},{ }^{29} \mathrm{Si} 79.47 \mathrm{MHz}$. Powdered samples were packed into a zirconia rotor with a $4.0 \mathrm{~mm}$ outer diameter. The spectra were obtained at a spin speed of $10 \mathrm{kHz}$, with a recycle delay of $2 \mathrm{~s}$ for ${ }^{1} \mathrm{H}, 0.2 \mathrm{~s}$ for ${ }^{27} \mathrm{Al}, 20 \mathrm{~s}$ for ${ }^{29} \mathrm{Si}$. Adamantane was used to reference the ${ }^{1} \mathrm{H}$ chemical shift, Aluminium nitrate was used to reference the ${ }^{27} \mathrm{Al}$ chemical shift, and TMS was used to reference the ${ }^{29} \mathrm{Si}$ chemical shift.

X-ray photoelectron spectroscopy (XPS) measurements were made on a Kratos Axis ultra DLD photoelectron spectrometer using a non-monochromatized $\mathrm{Mg} \mathrm{K} \alpha$ X-ray source $(\mathrm{h} v=1253.6 \mathrm{eV})$. An analyser pass energy of $50 \mathrm{eV}$ was used for survey scans and $20 \mathrm{eV}$ for detailed scans. Binding energies were referenced to the $\mathrm{C} 1 \mathrm{~s}$ peak from adventitious carbonaceous contamination, assumed to have a 
This is the peer reviewed version of the following article: Chem CatChem 2020, 12, 5236-5249, which has been published in final form at https://doi.org/10.1002/cctc.202000787. This article may be used for non-commercial purposes in accordance with Wiley Terms and Conditions for Use of Self-Archived Versions. binding energy of $284.6 \mathrm{eV}$. XPS data were analysed using CasaXPS software. The peak fitting of the spectra was performed using a set of mixed Gaussian-Lorentzian envelopes.

\section{Upgrading experiments}

Catalytic upgrading experiments were carried out in a fixed-bed reactor $\left(0.5 \mathrm{~g}\right.$ catalyst, $\left.\mathrm{GHSV}=5 \mathrm{~h}^{-1}\right)$ operating at atmospheric pressure using $\mathrm{N}_{2}$ as the carrier gas. A detailed description about the process and experimental protocol has been described previously ${ }^{[10 b, 11,14]}$. Briefly, the catalytic process was conducted at a temperature of $450{ }^{\circ} \mathrm{C}$ (atmospheric pressure). This temperature was monitored by a thermocouple placed at the top of the catalyst bed. $5 \mathrm{~mL} / \mathrm{h}$ of raw bio-oil were fed over 2 hours and the resulting volatile fraction was passed through an ice trap where liquids were recovered. Non-condensable gases were collected in a $25 \mathrm{~L}$ sampling bag for further characterization and the corresponding gas yield was calculated from the composition of the gas sampled. The other acquired by-products were grouped into different fractions. Firstly, liquids recovered in the condenser consisted of two immiscible layers which were separated into organic and aqueous fractions by a centrifugation-decantation method. The yield to each liquid fraction was determined by weight. Secondly, the solid residue consists of a mixture of char, tar, and coke. Char formation is inherent to reactor configuration and includes the solid fraction deposited on the top plug, which was gravimetrically assessed. Tar is the acetone soluble portion determined gravimetrically by evaporating the solvent after washing out the surface of the inner tube, and coke was calculated by the weight difference before and after heating the used catalyst in static air at $600{ }^{\circ} \mathrm{C}$ for $2 \mathrm{~h}$ (heating rate: $20^{\circ} \mathrm{C} / \mathrm{min}$ ). Total solid yield was calculated as a sum of char, tar and coke. Mass balance was determined as the sum of aqueous, organic, solid and gas fractions, always leading to values higher than $95 \%$. Three replicate runs were carried out for the acidic mesoporous zeolites, showing similar liquid, solid, and gas yields with an experimental error lower than $\pm 5.0 \%$.

\section{Bio-oil and non-condensable gas characterization}

Organic bio-oil fraction analysis was conducted to determining their ultimate composition (Carlo Erba EA1108), heating value (IKA C- 2000, according to UNE-EN ISO 18125:2018), water content by Karl Fischer titration (Crison Titromatic, according to ASTM E203-96), TAN and pH (Mettler Toledo T50). In addition, the deoxygenation rate (\% Deox) was calculated by excluding the amount of oxygen due to the water content in both the raw and upgraded bio-oil. This parameter was calculated following the equation: 
This is the peer reviewed version of the following article: ChemCatChem 2020, 12, 5236-5249, which has been published in final form at https://doi.org/10.1002/cctc.202000787. This article may be used for non-commercial purposes in accordance with Wiley Terms and Conditions for Use of Self-Archived Versions.

$\operatorname{Deox}(\%)=\frac{\left(\% \mathbf{0}-\% \mathbf{0}_{\mathbf{H} 20}\right)_{\text {Bio-oil feed }}-\left(\% \mathbf{0}-\% \mathbf{0}_{\mathbf{H} 20}\right)_{\text {Upgraded bio-oil }}}{\left(\% \mathbf{0}-\% \mathbf{0}_{\mathbf{H} 20}\right)_{\text {Bio-oil feed }}} \times 100$

where $\% \mathrm{O}$ is the oxygen content determined by elemental composition, and $\% \mathrm{O}$ H2O is the percentage of oxygen corresponding to the water content, which is calculated from the water content determined by the Karl Fischer method. Moreover, the chemical composition of the organic phase was analyzed by GC/MS using a Varian CP-3800 gas chromatograph connected to a Saturn 2200 ion trap mass spectrometer ${ }^{[11]}$. Specifically, a low-bleed capillary column, CP-Sil 8 CB: Phenyl 5\%, dimethylpolysiloxane $95 \%$ was used. The initial furnace temperature was $40{ }^{\circ} \mathrm{C}$ and was maintained for $4 \mathrm{~min}$. Then, a ramp speed of $4{ }^{\circ} \mathrm{C} / \mathrm{min}$ was implemented to reach the final column temperature $\left(300{ }^{\circ} \mathrm{C}\right)$. This temperature was kept for 16 min. The carrier gas used was He (BIP grade) with a constant column flow of $1 \mathrm{ml} / \mathrm{min}$. Injector, detector and transfer line temperatures were $300{ }^{\circ} \mathrm{C}, 220{ }^{\circ} \mathrm{C}$ and $300{ }^{\circ} \mathrm{C}$, respectively. $1 \mu \mathrm{L}$ of sample (1:25, \% by weight, in a mixture of $1: 1 \mathrm{CH} 2 \mathrm{Cl} 2: \mathrm{C} 2 \mathrm{H} 6 \mathrm{O})$ was injected using a split ratio 25:1 and a 7.5 min solvent delay. The MS operated in electronic ionization mode using a range of $35-550 \mathrm{~m} / \mathrm{z}$. Each peak was assigned to selected compounds according to the corresponding $\mathrm{m} / \mathrm{z}$ values, which were previously defined in the automatic library search NIST 2011. Each sample was analyzed in duplicate and results for each compound were computed as an average in terms of area (counts). The compounds identified in the liquid were divided into the following classes: phenols, acids, aldehydes, cyclic ketones, furans, cyclic hydrocarbons, aromatic hydrocarbons, polyaromatic hydrocarbons and esters.

The non-condensable gas fraction was determined by gas chromatography (GC) using a Varian 490-GC PRO coupled to a thermal conductivity detector. The chromatograph was equipped with a Molsieve $5 \AA$ column to analyze permanent gases $\left(\mathrm{H}_{2}, \mathrm{O}_{2}, \mathrm{~N}_{2}\right.$, and $\left.\mathrm{CO}\right)$ and with a HayeSep column to analyze $\mathrm{CO}_{2}$ and hydrocarbons $\left(\mathrm{C}_{2}-\mathrm{C}_{4}\right)$.

\section{Acknowledgements}

The authors would like to thank MINECO and FEDER for financial support (Project ENE2015-68320-R and MAT2017-84118-C2-1-R). The authors want also to thank the support from the Regional Aragon Government (DGA) under the research groups support program. Said Agouram and the SCSIE-UV are acknowledged for TEM support.

Keywords: Mesoporous ZSM-5 zeolites $•$ Magnesium $•$ Bio-oil upgrading $\bullet$ De-oxygenation $•$ Aromatics 
This is the peer reviewed version of the following article: ChemCatChem 2020, 12, 5236-5249, which has been published in final form at https://doi.org/10.1002/cctc.202000787. This article may be used for non-commercial purposes in accordance with Wiley Terms and Conditions for Use of Self-Archived Versions.

\section{References}

[1] a) X. Zhang, H. Lei, S. Chen, J. Wu, Green Chem. 2016, 18, 4145-4169; b) A. V. Bridgwater, Biomass Bioenergy 2012, 38, 68-94.

[2] a) T. Dickerson, J. Soria, Energies 2013, 6, 514-538; b) A. Sharma, V. Pareek, D. Zhang, Renewable and Sustainable Energy Rev. 2015, 50, 1081-1096.

[3] J. Lehto, A. Oasmaa, Y. Solantausta, M. Kytö, D. Chiaramonti, Appl. Energy 2014, 116, 178190.

[4] J. Fermoso, P. Pizarro, J. M. Coronado, D. P. Serrano, Encycl. of sustainability Sci. and Technol. 2017, 1-33.

[5] a) A. Bohre, M. I. Alam, K. Avasthi, F. Ruiz-Zepeda, B. Likozar, Appl. Catal., B 2020, 119069;

b) M. Grilc, B. Likozar, J. Levec, Biomass Bioenergy 2014, 63, 300-312; c) M. Grilc, G.

Veryasov, B. Likozar, A. Jesih, J. Levec, Appl. Catal., B 2015, 163, 467-477.

[6] G. Yildiz, F. Ronsse, R. V. Duren, W. Prins, Renewable Sustainable Energy Rev. 2016, 57, 1596-1610.

[7] a) M. E. Boot-Handford, E. Virmond, N. H. Florin, R. Kandiyoti, P. S. Fennell, Biomass Bioenergy 2018, 108, 398-414; b) D. Ro, Y.-M. Kim, I.-G. Lee, J. Jae, S.-C. Jung, S. C. Kim, Y.-K. Park, J. Cleaner Prod. 2018, 176, 298-303; c) A. Veses, M. Aznar, J. M. López, M. S. Callén, R. Murillo, T. García, Fuel 2015, 141, 17-22; d) A. Veses, M. Aznar, M. S. Callén, R. Murillo, T. García, Fuel 2016, 181, 430-437.

[8] P. S. Rezaei, H. Shafaghat, W. M. A. W. Daud, Appl. Catal., A 2014, 469, 490-511.

[9] a) H. Hassan, J. K. Lim, B. H. Hameed, Bioresour. Technol. 2016, 221, 645-655; b) Y. K. Park, M. L. Yoo, S. H. Jin, S. H. Park, Renewable Energy 2015, 79, 20-27; c) M. I. Jahirul, M. G. Rasul, A. A. Chowdhury, N. Ashwath, Energies 2012, 5, $4952-5001$. 
This is the peer reviewed version of the following article: ChemCatChem 2020, 12, 5236-5249, which has been published in final form at https://doi.org/10.1002/cctc.202000787. This article may be used for non-commercial purposes in accordance with Wiley Terms and Conditions for Use of Self-Archived Versions.

[10] a) J. Fermoso, P. Pizarro, J. M. Coronado, D. P. Serrano, Wiley Interdiscip. Rev.: Energy Environ. 2017, 6; b) B. Puértolas, A. Veses, M. S. Callén, S. Mitchell, T. García, J. PérezRamírez, ChemSusChem 2015, 8, 3283-3293.

[11] A. Veses, B. Puértolas, J. M. López, M. S. Callén, B. Solsona, T. García, ACS Sustainable Chem. Eng. 2016, 4, 1653-1660.

[12] a) A. N. Kay Lup, F. Abnisa, W. M. A. W. Daud, M. K. Aroua, Appl. Catal., A 2017, 541, 87106; b) M. O. Adebajo, M. A. Long, R. L. Frost, Spectrochim. Acta, Part A 2004, 60, 791-799.

[13] E. Saraçoğlu, B. B. Uzun, E. Apaydın-Varol, Int. J. Hydrogen Energy 2017, 42, 21476-21486.

[14] A. Veses, B. Puértolas, M. S. Callén, T. García, Microporous and Mesoporous Mater. 2015, 209, 189-196.

[15] a) A. Dyer, T. I. Emms, J. Mater. Chem. 2005, 15, 5012-5021; b) G. M. Lee, N. H. Heo, K. Seff, Microporous and Mesoporous Mater. 2017, 244, 47-49; c) H. Zhang, J. Zheng, R. Xiao, BioResources 2013, 8, 5612-5621.

[16] J. Li, Y. Yu, X. Li, W. Wang, G. Yu, S. Deng, J. Huang, B. Wang, Y. Wang, Appl. Catal., B 2015, 172-173, 154-164.

[17] D. Mao, W. Yang, J. Xia, B. Zhang, Q. Song, Q. Chen, J. Catal. 2005, 230, 140-149.

[18] H. Hernando, I. Moreno, J. Fermoso, C. Ochoa-Hernández, P. Pizarro, J. M. Coronado, J. Čejka, D. P. Serrano, Biomass Convers. Biorefin 2017, 7, 289-304.

[19] C. Chen, Q. Zhang, Z. Meng, C. Li, H. Shan, Appl. Petrochem. Res. 2015, 5, 277-284.

[20] a) H. J. Park, H. S. Heo, J. K. Jeon, J. Kim, R. Ryoo, K. E. Jeong, Y. K. Park, Appl. Catal., B 2010, 95, 365-373; b) H. J. Park, J. I. Dong, J. K. Jeon, K. S. Yoo, J. H. Yim, J. M. Sohn, Y. K. Park, J. Ind. Eng. Chem. 2007, 13, 182-189.

[21] M. Thommes, K. Kaneko, V. Neimark Alexander, P. Olivier James, F. Rodriguez-Reinoso, J. Rouquerol, S. W. Sing Kenneth, Pure Appl. Chem., 2015, 87, 1051.

[22] Y. Zheng, F. Wang, X. Yang, Y. Huang, C. Liu, Z. Zheng, J. Gu, J. Anal. Appl. Pyrolysis 2017, 126, 169-179.

[23] J. Fermoso, H. Hernando, P. Jana, I. Moreno, J. Přech, C. Ochoa-Hernández, P. Pizarro, J. M. Coronado, J. Čejka, D. P. Serrano, Catal. Today 2016, 277, 171-181.

[24] a) P. Shestakova, C. Martineau, V. Mavrodinova, M. Popova, RSC Adv. 2015, 5, 81957-81964;

b) S. Sklenak, P. C. Andrikopoulos, B. Boekfa, B. Jansang, J. Nováková, L. Benco, T. Bucko, J. Hafner, J. Dědeček, Z. Sobalík, J. Catal. 2010, 272, 262-274; c) I. Rashid, N. H. Daraghmeh, M. M. Al Omari, B. Z. Chowdhry, S. A. Leharne, H. A. Hodali, A. A. Badwan, Profiles Drug Subst., Excipients, Relat. Methodol.2011, 36, 241-285; d) V. Antochshuk, M. Jaroniec, S. H. Joo, R. Ryoo, Stud. Surf. Sci. Catal., 2002, 141, 607-614. 
This is the peer reviewed version of the following article: ChemCatChem 2020, 12, 5236-5249, which has been published in final form at https://doi.org/10.1002/cctc.202000787. This article may be used for non-commercial purposes in accordance with Wiley Terms and Conditions for Use of Self-Archived Versions.

[25] a) D. Coster, A. L. Blumenfeld, J. J. Fripiat, J. Phys. Chem. 1994, 98, 6201-6211; b) J.

Hargreaves, D. Jackson, Met. Oxide Catal., 2009, 195-242; c) M. H. Lee, C.-F. Cheng, V.

Heine, J. Klinowski, Chem. Phys. Lett. 1997, 265, 673-676; d) C. Pecharromán, I. Sobrados, J.

E. Iglesias, T. González-Carreño, J. Sanz, J. Phys. Chem. B 1999, 103, 6160-6170; e) P. Paluch,

N. Potrzebowska, A. M. Ruppert, M. J. Potrzebowski, Solid State Nucl. Magn. Reson. 2017, 84, 111-117.

[26] W. Ding, Y. Cui, J. Li, Y. Yang, W. Fang, RSC Adv. 2014, 4, 50123-50129.

[27] I. Graça, D. Iruretagoyena, D. Chadwick, Appl. Catal., B 2017, 206, 434-443.

[28] a) D. Freude, J. Klinowski, H. Hamdan, Chem. Phys. Lett. 1988, 149, 355-362; b) M. Hunger,

D. Freude, H. Pfeifer, H. Bremer, M. Jank, K. P. Wendlandt, Chem. Phys. Lett. 1983, 100, 29-

33; c) H. Pfeifer, J. Chem. Soc., Faraday Trans. 1 1988, 84, 3777-3783; d) J. L. White, L. W.

Beck, J. F. Haw, J. Am. Chem. Soc. 1992, 114, 6182-6189; e) M. Hunger, Solid State Nucl.

Magn. Reson. 1996, 6, 1-29.

[29] J. M. Rimsza, E. G. Sorte, T. M. Alam, ACS Omega 2019, 4, 1033-1044.

[30] a) P. Y. Wu, Y. P. Jiang, Q. Y. Zhang, Y. Jia, D. Y. Peng, W. Xu, New J. Chem. 2016, 40, 2878-

2885; b) L. Pandolfi, P. Cafarelli, S. Kaciulis, A. A. G. Tomlinson, Microporous and

Mesoporous Mater. 2008, 110, 64-71.

[31] Y.-T. Cheng, J. Jae, J. Shi, W. Fan, G. W. Huber, Angew. Chem., Int. Ed 2012, 51, 1387-1390.

[32] Q. Bu, H. Lei, A. H. Zacher, L. Wang, S. Ren, J. Liang, Y. Wei, Y. Liu, J. Tang, Q. Zhang, R.

Ruan, Bioresour. Technol. 2012, 124, 470-477.

[33] M. Kruesi, Z. R. Jovanovic, A. Steinfeld, Fuel 2014, 117, 680-687.

[34] A. G. Gayubo, A. T. Aguayo, A. Atutxa, R. Prieto, J. Bilbao, Energy Fuels 2004, 18, 16401647.

[35] a) A. Oasmaa, C. Peacocke, VTT Publications, 2010, 2-65; b) A. V. Bridgwater, G. V. C.

Peacocke, Renewable Sustainable Energy Rev. 2000, 4, 1-73.

[36] Y. Liu, Z. Li, J. J. Leahy, W. Kwapinski, Energy Fuels 2015, 29, 3691-3698.

[37] R. Kumar, N. Enjamuri, S. Shah, A. S. Al-Fatesh, J. J. Bravo-Suárez, B. Chowdhury, Catal.Today 2018, 302, 16-49.

[38] S. D. Stefanidis, S. A. Karakoulia, K. G. Kalogiannis, E. F. Iliopoulou, A. Delimitis, H.

Yiannoulakis, T. Zampetakis, A. A. Lappas, K. S. Triantafyllidis, Appl. Catal., B 2016, 196, 155-173.

[39] B. Puértolas, T. C. Keller, S. Mitchell, J. Pérez-Ramírez, Appl. Catal., B 2016, 184, 77-86.

[40] G. J. Hutchings, P. Johnston, D. F. Lee, A. Warwick, C. D. Williams, M. Wilkinson, J. Catal. 1994, 147, 177-185. 
This is the peer reviewed version of the following article: Chem CatChem 2020, 12, 5236-5249, which has been published in final form at https://doi.org/10.1002/cctc.202000787. This article may be used for non-commercial purposes in accordance with Wiley Terms and Conditions for Use of Self-Archived Versions.

[41] J. Li, Y. Wei, G. Liu, Y. Qi, P. Tian, B. Li, Y. He, Z. Liu, Catal.Today 2011, 171, $221-228$.

[42] a) C. Liu, H. Wang, A. M. Karim, J. Sun, Y. Wang, Chemical Society Reviews 2014, 43, 75947623; b) S. Wang, G. Dai, H. Yang, Z. Luo, Prog. Energy Combust. Sci. 2017, 62, 33-86.

[43] G. Pacchioni, ACS Catalysis 2014, 4, 2874-2888.

[44] a) G. W. Huber, S. Iborra, A. Corma, Chem. Rev. 2006, 106, 4044-4098; b) V. Dhyani, T. Bhaskar, Renewable Energy 2018, 129, 695-716.

[45] a) J. D. Martínez, R. Murillo, T. García, A. Veses, J. Hazard. Mater. 2013, 261, 637-645; b) J.

D. Martínez, A. Veses, A. M. Mastral, R. Murillo, M. V. Navarro, N. Puy, A. Artigues, J.

Bartrolí, T. García, Fuel Process. Technol. 2014, 119, 263-271.

[46] A. Veses, M. Aznar, I. Martínez, J. D. Martínez, J. M. López, M. V. Navarro, M. S. Callén, R. Murillo, T. García, Bioresour. Technol. 2014, 162, 250-258.

[47] D. Verboekend, S. Mitchell, M. Milina, J. C. Groen, J. Pérez-Ramírez, J. Phys. Chem. C 2011, $115,14193-14203$.

[48] C. A. Emeis, J.Catal. 1993, 141, 347-354.

\section{Table of Contents}

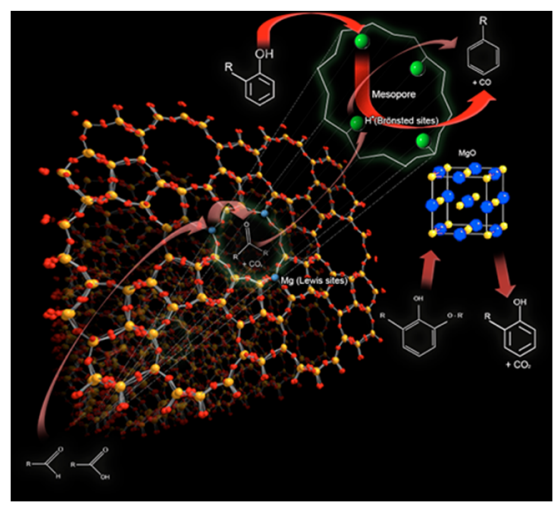

Significantly higher deoxygenation rates can be achieved using Mg-loaded mesoporous ZSM-5 zeolites compared to parent acidic counterparts. This catalytic performance has been linked to the simultaneous presence of different active sites after Mg impregnation such as $\mathrm{MgO}$ nanoparticles, internal strong Lewis acidic sites created by the interaction between $\left(\mathrm{Mg}^{2+} \mathrm{OH}^{-}\right)^{+}$species and extra framework alumina and remaining Brønsted acidic sites at the external surface. 
This is the peer reviewed version of the following article: ChemCatChem 2020, 12, 5236-5249, which has been published in final form at https://doi.org/10.1002/cctc.202000787. This article may be used for non-commercial purposes in accordance with Wiley Terms and Conditions for Use of Self-Archived Versions. 